\title{
Key features for more successful place-based sustainability research on social-ecological systems: a Programme on Ecosystem Change and Society (PECS) perspective
}

\author{
$\underline{\text { Patricia Balvanera }}^{1}$, Tim M. Daw $^{2}$, Toby A. Gardner $^{3}$, Berta Martín-López $^{4}, \underline{\text { Albert V. Norström }}^{2}$, Chinwe Ifejika Speranza $^{5,6}$, Marja $^{\text {Spla }}$

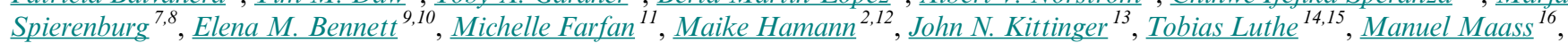 \\ Garry D. Peterson ${ }^{2}$ and Gustavo Perez-Verdin ${ }^{17}$
}

\begin{abstract}
The emerging discipline of sustainability science is focused explicitly on the dynamic interactions between nature and society and is committed to research that spans multiple scales and can support transitions toward greater sustainability. Because a growing body of place-based social-ecological sustainability research (PBSESR) has emerged in recent decades, there is a growing need to understand better how to maximize the effectiveness of this work. The Programme on Ecosystem Change and Society (PECS) provides a unique opportunity for synthesizing insights gained from this research community on key features that may contribute to the relative success of PBSESR. We surveyed the leaders of PECS-affiliated projects using a combination of open, closed, and semistructured questions to identify which features of a research project are perceived to contribute to successful research design and implementation. We assessed six types of research features: problem orientation, research team, and contextual, conceptual, methodological, and evaluative features. We examined the desirable and undesirable aspects of each feature, the enabling factors and obstacles associated with project implementation, and asked respondents to assess the performance of their own projects in relation to these features. Responses were obtained from 25 projects working in 42 social-ecological study cases within 25 countries. Factors that contribute to the overall success of PBSESR included: explicitly addressing integrated social-ecological systems; a focus on solutionand transformation-oriented research; adaptation of studies to their local context; trusted, long-term, and frequent engagement with stakeholders and partners; and an early definition of the purpose and scope of research. Factors that hindered the success of PBSESR included: the complexities inherent to social-ecological systems, the imposition of particular epistemologies and methods on the wider research group, the need for long periods of time to initiate and conduct this kind of research, and power asymmetries both within the research team and among stakeholders. In the self-assessment exercise, performance relating to team and context-related features was ranked higher than performance relating to methodological, evaluation, and problem orientation features. We discuss how these insights are relevant for balancing place-based and global perspectives in sustainability science, fostering more rapid progress toward inter- and transdisciplinary integration, redefining and measuring the success of PBSESR, and facing the challenges of academic and research funding institutions. These results highlight the valuable opportunity that the PECS community provides in helping build a community of practice for PBSESR.
\end{abstract}

Key Words: interdisciplinarity; PECS; solutions; stakeholders; transdisciplinarity; transformations

\section{INTRODUCTION}

One consequence of the increased impact of human activities on the biosphere has been a growing recognition of the dependence of societal well-being on the life-support system of the planet (Millennium Ecosystem Assessment 2005). This recognition has underpinned research that views ecological, economic, and social systems as interlinked and inseparable social-ecological systems (SESs; Berkes and Folke 1998, Folke 2006, Ostrom 2009). We are increasingly aware of the multiple ways in which people shape ecosystems, from local to global scales, and how we are fundamentally dependent on the capacity of these systems to support human prosperity and societal development. This same body of research has also led to a better understanding of how environmental, economic, and societal change processes are dynamically interlinked, and how an understanding of these connections is critical in efforts to foster more sustainable environmental stewardship (Chapin et al. 2009). Despite these advances, the potential benefits of adopting a SESs perspective to improve sustainability outcomes through research are far from being fully realized (Bennett et al. 2015, Fischer et al. 2015).

As social-ecological approaches to sustainability research are becoming increasingly prevalent, a growing body of literature is

\footnotetext{
${ }^{1}$ Instituto de Investigaciones en Ecosistemas y Sustentabilidad, Universidad Nacional Autónoma de México, ${ }^{2}$ Stockholm Resilience Centre, Stockholm University, ${ }^{3}$ Stockholm Environment Institute, ${ }^{4}$ Leuphana University of Lüneburg, Faculty of Sustainability, Institute of Ethics and Transdisciplinary Sustainability Research, Lüneburg, Germany, ${ }^{5}$ Department of Geography, University of Bonn, Germany, ${ }^{6}$ Centre for Development and Environment/Institute of Geography, University of Bern, Switzerland, ${ }^{7}$ Department of Anthropology and Development Studies, Radboud University Nijmegen, The Netherlands, ${ }^{8}$ Department of Sociology and Social Anthropology, Stellenbosch University, South Africa, ${ }^{9}$ Department of Natural Resource Sciences, McGill University, ${ }^{10}$ McGill School of Environment, McGill University, ${ }^{11}$ Departamento de Ingeniería Geomática e Hidráulica, Universidad de Guanajuato, Mexico, ${ }^{12}$ Centre for Complex Systems in Transition, Stellenbosch University, South Africa, ${ }^{13}$ Conservation International, Center for Oceans, Global Fisheries and Aquaculture Program, Honolulu, Hawaii, USA, ${ }^{14}$ University of Applied Sciences HTW Chur, Switzerland, ${ }^{15}$ MonViso Institute, Ostana, Italy, ${ }^{16}$ Instituto de Investigaciones en Ecosistemas y Sustentabilidad (IIES), Universidad Nacional Autónoma de México (UNAM), ${ }^{17}$ Instituto Politécnico Nacional, CIIDIR Durango, Mexico
} 
aimed at identifying the features that enable social-ecological research to bring about positive and tangible change toward sustainability (Folke 2006, Clark 2007, Pretty 2011, Lang et al. 2012, Cheruvelil et al. 2014, Fischer et al. 2014). Social-ecological research, as a form of sustainability science, is a scientific endeavor that aspires to generate knowledge through problem- or solutionoriented processes that include engagement and collaboration with actors from outside academia (Lang et al. 2012, MartínLópez and Montes 2015), often with a focus on specific places and contexts (Fischer et al. 2014).

Over the past decades, various research networks have emerged to facilitate the development and synthesis of social-ecological research. Some of those networks of researchers include the Farming Systems for Development Approach (Shaner et al. 1982) and the Ecoregional approach (Sharma et al. 1996), and they have focused on agroecosystems and how sustainable agricultural production can be delivered. Other networks have focused on either the ecological or the social components of SESs. For example, Ostrom's Workshop in Political Theory and Policy Analysis at Indiana University pioneered synthetic work on smallscale common-pool resource systems that was mostly focused on governance and institutions (Brondizio et al. 2009). The International Long-Term Ecological Research (ILTER) network has focused on ecological patterns and processes within reserves, but has increasingly begun to expand its research activities beyond conservation areas and to adopt a place-based, long-term, socialecological research approach (Maass and Equihua 2015, Maass et al. 2016). A number of syntheses of social-ecological dynamics across multiple case studies have been coordinated by the Resilience Alliance, a consortium of research groups and research institutes from across many disciplines (Walker et al. 2006).

The definition and assessment of the success of place-based social-ecological sustainability research (PBSESR) remains a challenge. PBSESR needs to meet the dual challenge of assessing and understanding complex and dynamic SESs while fostering a genuinely transdisciplinary process that is capable of facilitating knowledge exchange across disciplinary boundaries and between researchers and users (Miller et al. 2008, Lang et al. 2012). Current challenges for sustainability research include determining: how such research is initiated and framed, how practitioners are involved, how the research is funded, how established academic disciplines are integrated with practical knowledge and what new methods are capable of achieving such integration, what type of outreach and communication is relevant and generates impact, and how progress and success are generally measured and defined (Walter et al. 2007, Lang et al. 2012, Mori and Christodoulou 2012, Brandt et al. 2013).

Here, we adopt a working definition of successful research projects as those that enhance social-ecological understanding among both research and user communities while engendering actionable policy or management recommendations and options. Understanding the features that have enabled or prevented research projects from being more or less successful in this regard remains an urgent challenge.

Insights on what may characterize and contribute to successful PBSESR projects can be drawn from experience and comparisons across sites (Lang et al. 2012, Fischer et al. 2014) or by revising past or current sustainability research programs (Mooney 2016,
Turner et al. 2016). Here, we focus on insights gained by one grouping of such projects that are associated with the Programme on Ecosystem Change and Society (PECS; Carpenter et al. 2012; http://www.pecs-science.org). PECS evolved from a longstanding search for increasing interdisciplinary perspectives within international global change research programs (Fig. 1) that gradually incorporated a range of scientists to address the interlinkages between climate, ecosystem function, biodiversity, and societal needs (Leemans 2016). The Millennium Ecosystem Assessment (MEA) went beyond previous evaluations, not only in its disciplinary breadth, but also in the depth of the socialecological analysis (Norgaard 2008). However, MEA participants were surprised by the still highly compartmentalized scientific approaches of much of the research that the MEA drew upon and the difficulties in obtaining integration. As a result of the insights gained from the Intergovernmental Panel on Climate Change and the MEA, a major shift toward transdisciplinary sustainability science occurred in the search to address the present and future needs of society (Mooney et al. 2013, Leemans 2016). Future Earth was then created using innovative research approaches and governance structures to bring sustainability research in developed and developing countries into the mainstream. PECS is, in a way, an early experiment toward the conceptualization and operationalization of Future Earth, where integration across disciplines, stakeholders, and study sites was seeded. The need for a new 10-yr global research program to foster coordinated research for understanding the dynamic relationship between humans and ecosystems by focusing on specific research sites emerged as a recommendation made by the ad hoc expert group assigned to evaluate the MEA process (ICSU-UNESCOUNU 2008).

Fig. 1. The evolution of global research projects and the case of the Programme for Ecosystem Change and Society.

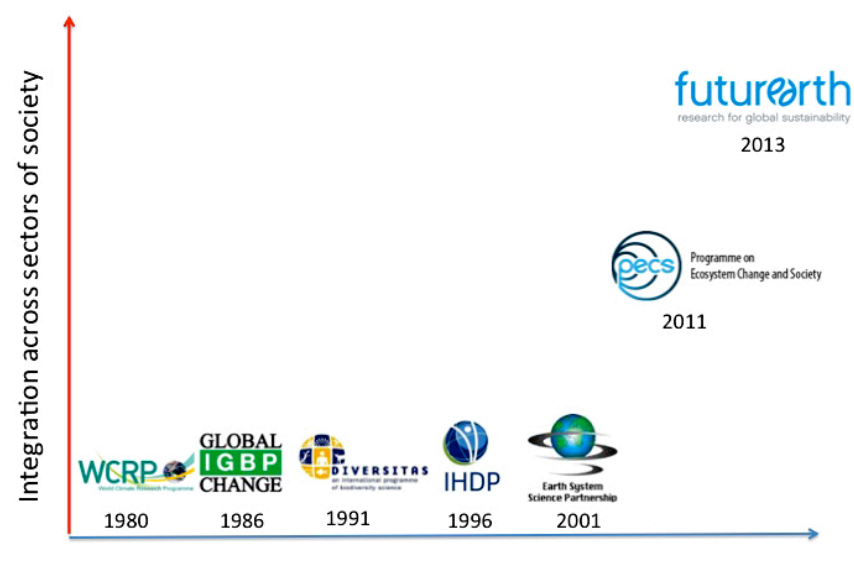

Integration across scientific disciplines

Launched in 2011, the motivation for PECS is to support a more focused and in-depth understanding of SESs and opportunities to foster sustainable stewardship (Carpenter et al. 2012). The principal approach of PECS research is through comparisons of place-based, long-term, social-ecological case studies. To date, 15 projects have been endorsed by PECS, and these together cover 
42 regional case studies around the world that apply a SESs approach and aim to combine different processes of knowledge generation through a transdisciplinary process. A further set of case studies and researchers are involved in PECS as part of the different inter- and transdisciplinary working groups that focus on different crosscutting topics.

Here, we seek to identify key insights and opportunities for improving the practice of PBSESR that have emerged from the PECS community. We do so by surveying existing projects endorsed by and associated with PECS. We first characterized the projects that were included in this survey. A semantic network analysis based on the projects' abstracts allowed for a characterization of convergent or divergent concepts of PBSESR for the projects assessed. We then reviewed the key research features that have been considered by other scholars of sustainability science (Zierhofer and Burger 2007, Hirsch Hadorn et al. 2008, Lang et al. 2012) and conducted our assessment based on six complementary and interrelated types of research features: problem orientation; research team; and contextual, conceptual, methodological, and evaluative features. For each of these features, we surveyed respondents from different PECS projects to identify specific (desirable or undesirable) attributes considered to be important as well as the factors that either enabled or constrained the ability of researchers to improve the design and implementation of their research. We also report on subjective self-assessment measures of the performance of surveyed projects with respect to the different features examined. In summary, we reflect on the lessons that project leaders learned while undertaking PBSESR about what has been successful and what has failed.

\section{METHODS}

\section{Survey design}

Our aim and general methodological approach were initially discussed at a PECS workshop held in Stockholm, Sweden, in September 2013. This was the inaugural workshop of PECS and included the Principal Investigators (PIs) and co-PIs of the projects endorsed by PECS as well as the members of the scientific committee. A pilot online survey was sent to the participants of a follow-up PECS workshop held in Moureze, France, in May 2014, including students, researchers, and project leaders.

Based on the pilot survey, we identified six overarching features that together can help describe the makeup of a given PBSESR project. These categories are closely interrelated and contribute toward work in all phases of the project, i.e., planning, development, and closure: problem orientation, contextual, conceptual, methodological, research team, and evaluative features. Problem orientation features capture how a project is conceived and designed, how the problem (or problem set) is chosen, who is involved in this process of problem identification, and what key steps are involved in project conception and design. Contextual features deal with the particular context of a research site (geographic, spatial, and temporal scales; socioeconomic, political, and historical contexts) and research process (institutional setting, funding, and connections with stakeholders) that can have a profound influence on the type of work that is conducted. Conceptual features capture the key themes, concepts, and conceptual frameworks of a given research project.
Methodological features describe the tools and types of methodological approaches of a given research project. Research team features describe the nature of the team, including which researchers and actors are included, their skills, as well as the nature of interactions among participants. Evaluative features relate to the outputs and outcomes of a given project, including those promised to the funders, those agreed upon with the stakeholders, those that emerge from the project as intended or unintended effects on local decision making and actionable policy, as well as additional goals held by the researchers involved.

\section{Data acquisition and analysis}

The full online survey (Appendix 1) was circulated to the entire PECS community (including endorsed projects and those in which members of the PECS scientific committee were involved) during September and October 2014. The survey was largely responded to by PIs and co-PIs (24) of the projects, as well as one PhD student and two postdocs.

The survey addressed the six aforementioned features for each of the projects. Information on the project objectives, location of study sites, number and type of research and stakeholder participants, start and end dates, historical legacies, and outcomes of the project were gathered and synthesized in tables. Abstracts of the projects were used to identify common keywords based on a semantic network analysis to characterize further the sets of projects assessed here and visualised with VibrantData (http:// vibrantdata.io).

We asked respondents to identify attributes they considered to be of particular importance for each of the features. Respondents also identified any desirable or undesirable aspects of these features, as well as the enabling factors and barriers that together determine the form that a given project takes. The survey was divided into sections for each of the features, with four sets of questions: (1) semistructured questions that aimed to identify desirable and undesirable aspects of the features, as well as enabling factors and obstacles associated with the features; (2) open questions that sought to obtain any other insights from respondents regarding each feature that would be useful to other scholars who undertake this kind of research; (3) closed questions that ranked the relative importance of the analyzed features and particular attributes in each feature; and (4) closed questions that asked about the current performance of the projects with respect to desirable aspects of key features.

We grouped the responses to the semistructured and open questions into similar themes, which were discovered by using the grounded theory approach (Strauss and Corbin 1990, Thomas and James 2006). Individual responses were coded against a set of descriptors that were designed to identify common themes that emerged within and among individual responses, and to capture the key elements of such common themes. Given the large overlap of responses within and among types of features, results were reorganized into three sections: (1) What contributes to success of PBSESR? (2) What hinders the success of PBSESR (including both crosscutting and specific issues)? (3) How are current projects performing for the analyzed features? For each of these sections, we separated features that have enabled from those that have hindered social-ecological research projects to achieve success. We then compared self-attributed progress among types of features. We avoided using quantitative measures of the 
Fig. 2. Map of the locations of case studies included in our analysis. See Table 1 for individual project details.

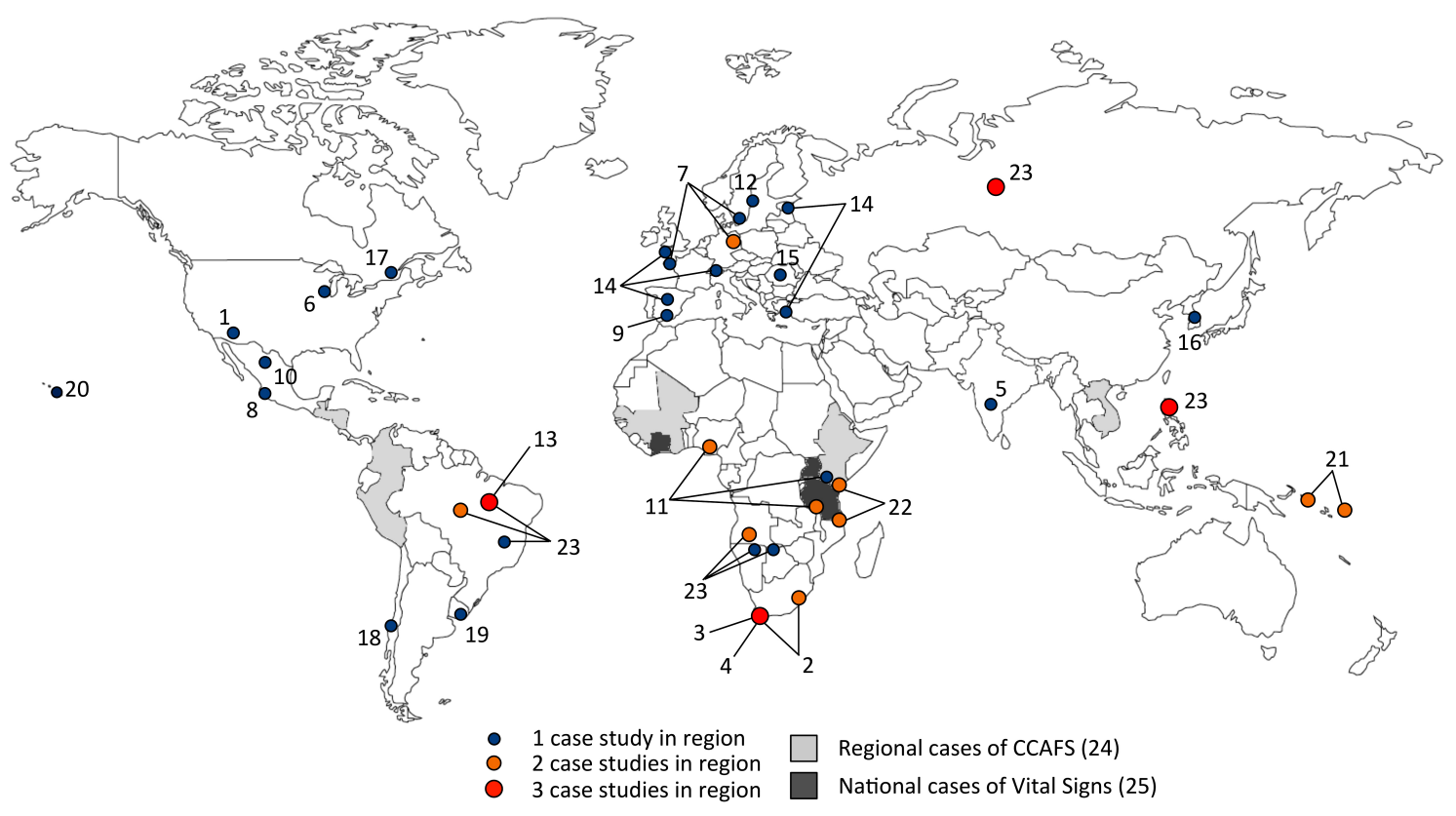

frequency of the different types of responses given the large overlaps across types of features and the largely unequal numbers of responses received per question.

\section{RESULTS}

\section{Participating projects}

A total of 27 researchers responded to the survey, representing 25 projects; 9 projects were endorsed by PECS, and the remainder were associated with members of the PECS scientific committee. Together, the projects represented 42 specific social-ecological case studies located in 25 different countries across five regions (Fig. 2): Africa (13 case studies), Europe (12), Oceania (4), North America (3), Latin America (5), and Asia (3). PIs of these projects were spread across these regions, although they were biased toward Europe (16), with decreasing representation from Latin America (6), North America (5), Africa (3), Asia (3), and Oceania (1).

Although projects naturally differed in their specific research focus, they all built on a platform of place-based research that addresses different social-ecological dynamics of landscapes, seascapes, or coastal regions (Table 1). The analysis of convergence and divergence in the projects' conceptual and thematic approaches to PBSESR, mapped trough a semantic network analysis of common keywords, revealed three interconnected clusters of convergent projects (Fig. 3). The clusters focused on sustainable land management, ecosystem services, or coastal SESs. The cluster of projects around ecosystem services was the tightest; these projects are most common to each other in terms of shared thematic and conceptual approaches to PBSESR. The coastal and land-management clusters differed largely because of the type of SES and the importance of adaptation in coastal systems. The conceptual convergence among the projects is confirmed by the three conceptually bridging projects (projects 9,15 , and 25) that are thematically closer to projects of the other clusters. Although they were not the most central projects within their clusters (i.e., most demonstrative for the concepts and themes existent in the clusters and visualized by node size), the three bridging projects best encompassed the different dimensions of PBSESR, including knowledge coproduction, solutions orientation, and integration of a range of stakeholders, as do most of the other projects but to a lesser extent.

Most of the projects (20) evolved from a previous legacy (Table 1). These legacies included earlier collaborations among some of the scientists on the team, conceptual insights obtained in earlier projects, long established research sites, or earlier interactions with local stakeholders.

The size of the projects, both in terms of directly funded personnel and number of associated case studies, differed substantially. The number of people directly linked or funded by the projects ranged from 2 to 45 individuals, and the number of case studies ranged from one to five (Table 1). All of the projects directly or indirectly involved stakeholders from different sectors, including local, state, and national governments; business representatives; nongovernmental organizations (NGOs); and owners or ecosystem managers in the respective case studies. Representatives from local governments and owners or ecosystem managers were involved in 16 of the projects, making these the most common nonacademic stakeholder group. The least common stakeholder group, with involvement in only one project, was national government.

Primary funding for the projects was mostly secured from national funding agencies (17 projects; Table 1). Regional agencies (e.g., 
Ecology and Society 22(1): 14

http://www.ecologyandsociety.org/vol22/iss1/art14/

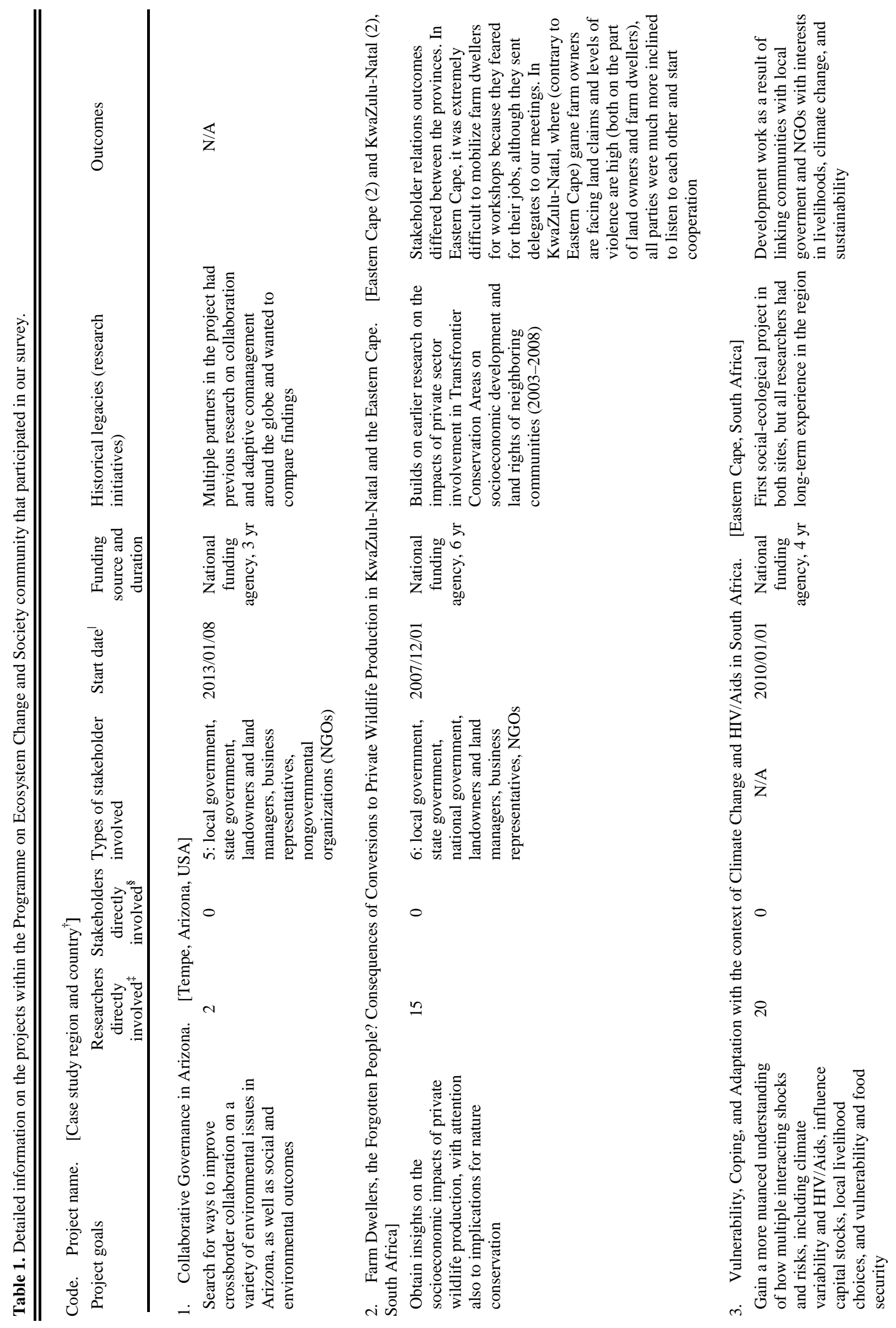




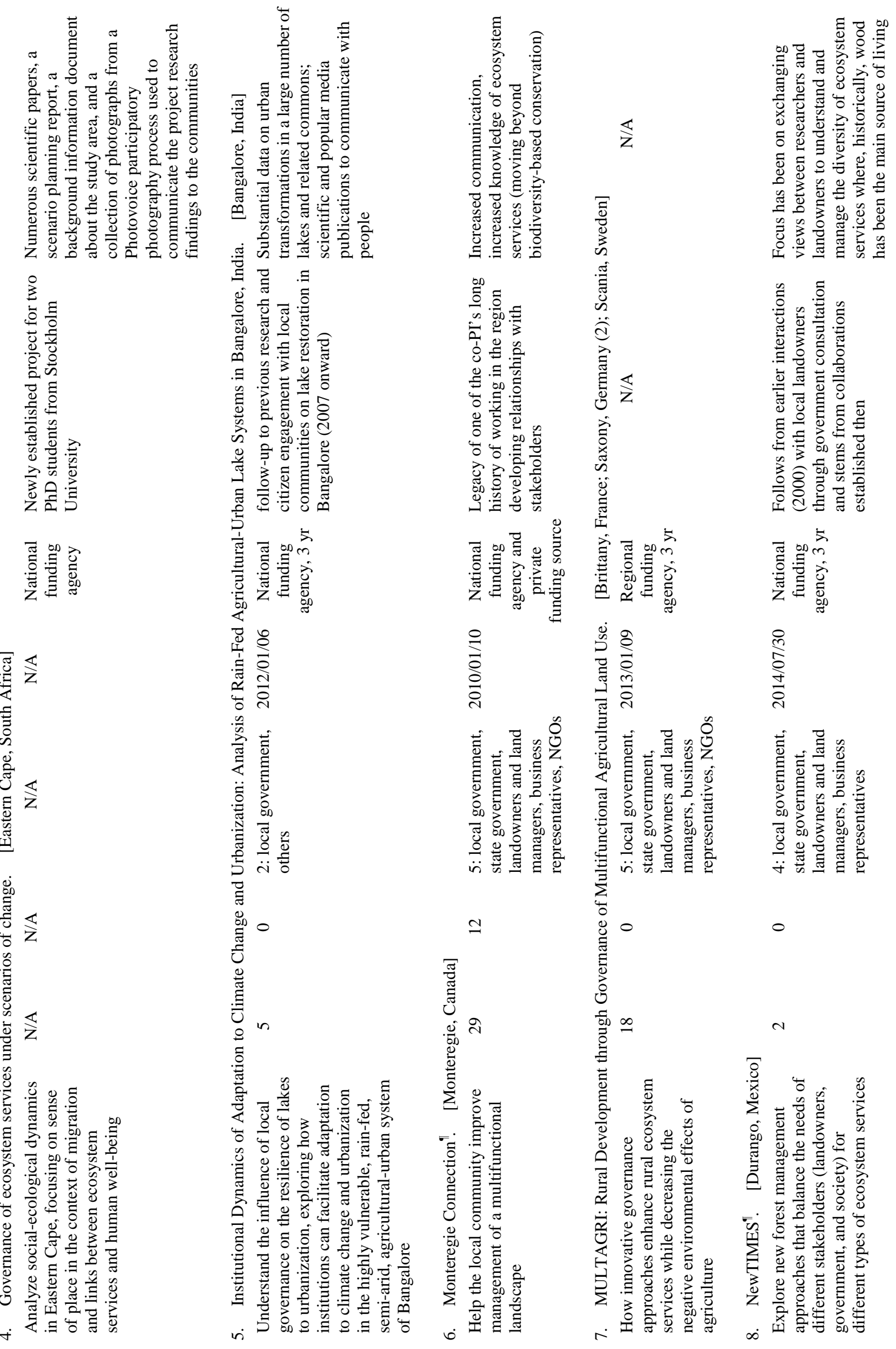



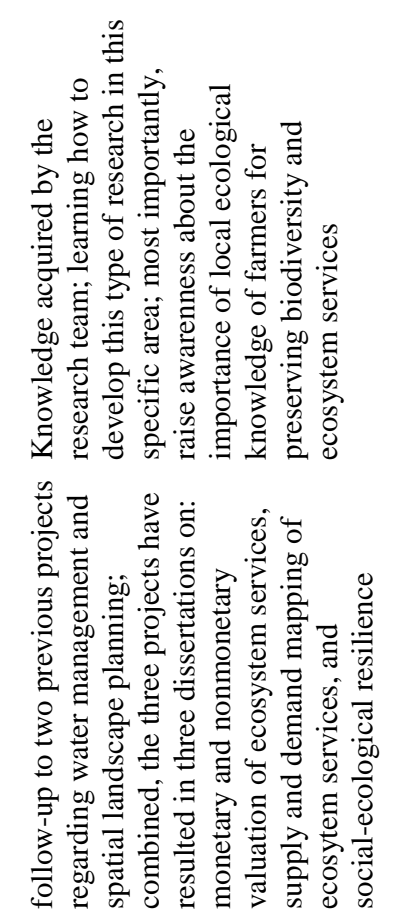

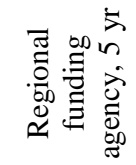
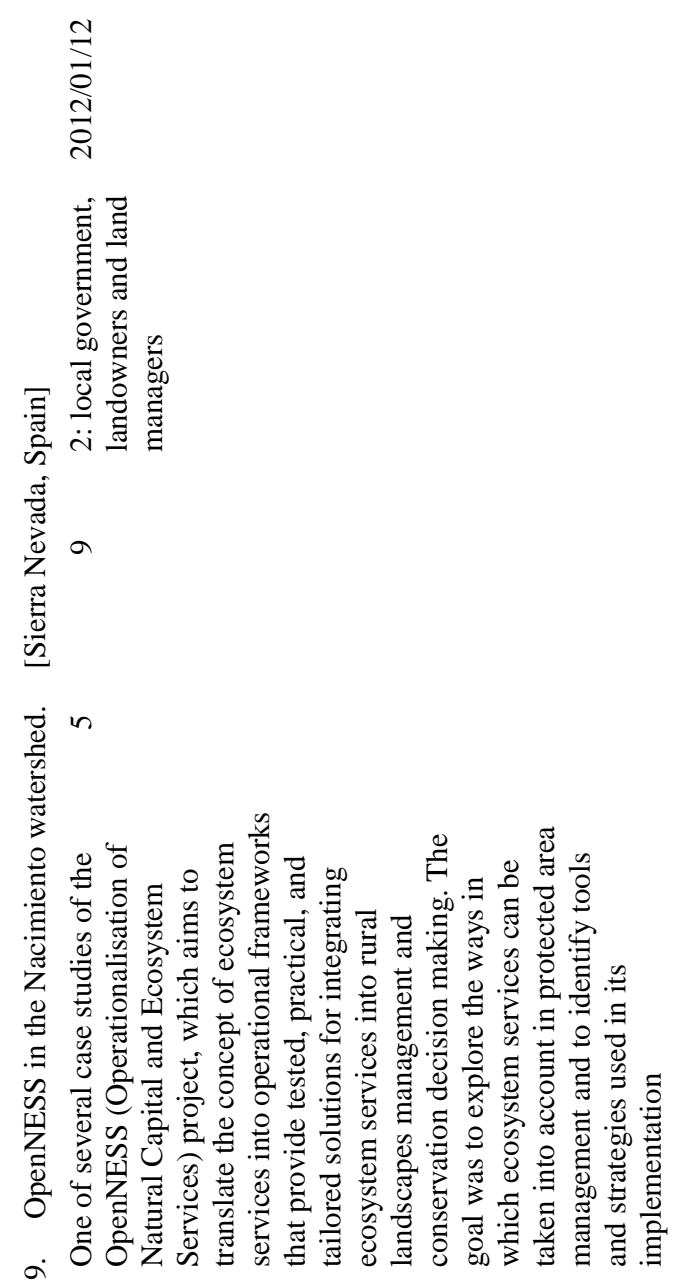
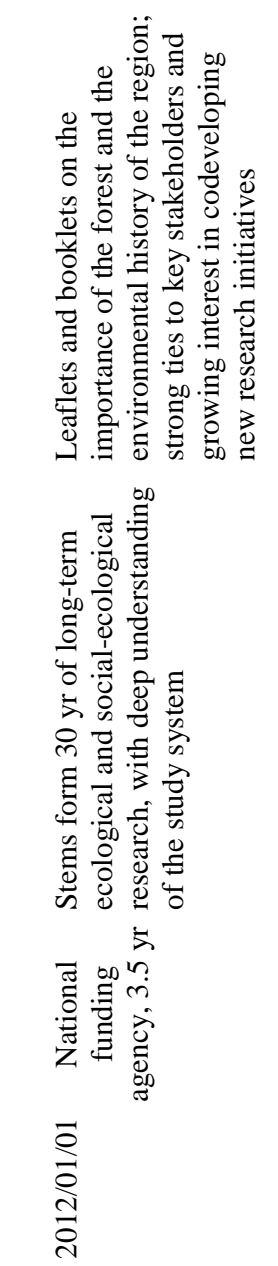

¿্ৰ

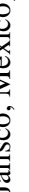

递

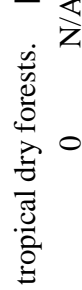

吾

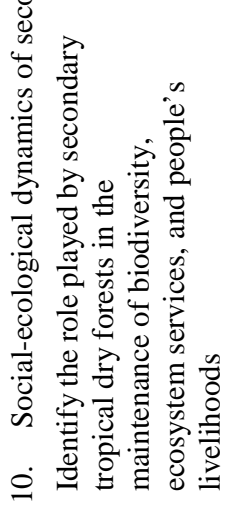

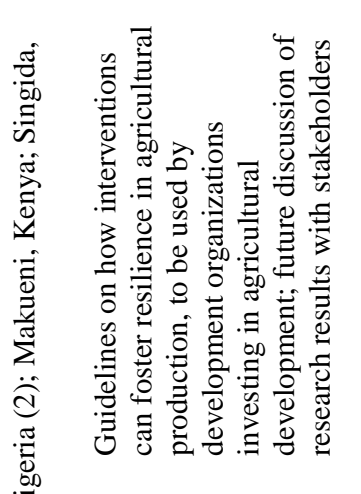

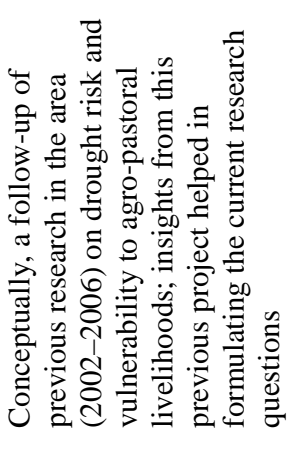

离

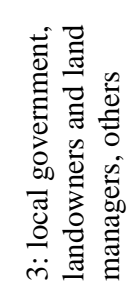

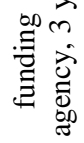

$+$

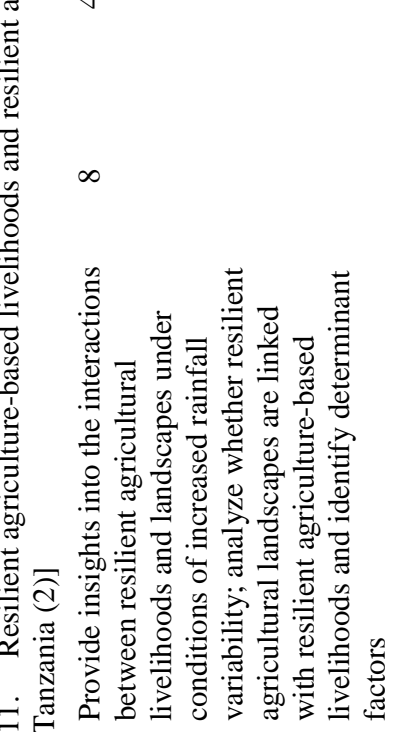



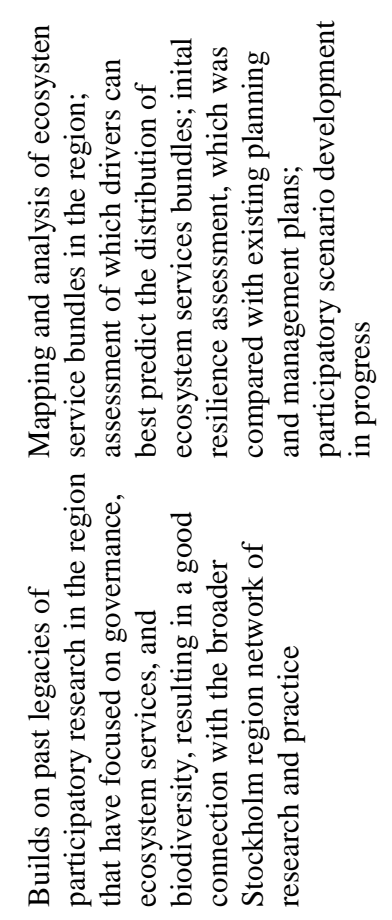

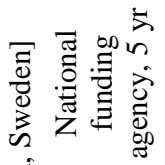

हี

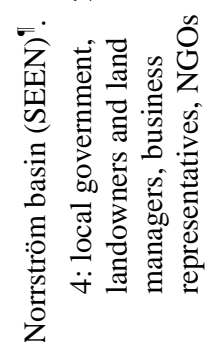

$\stackrel{0}{\stackrel{\Xi}{\Xi}} 0$

8

总

๑

离

苍芯

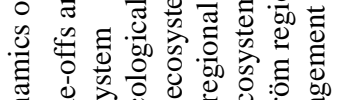

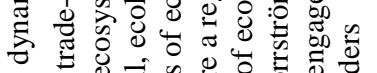
ส

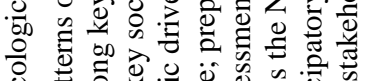

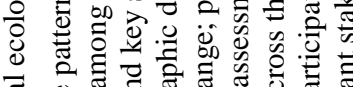

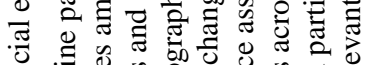

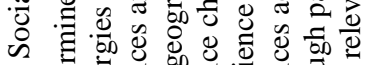

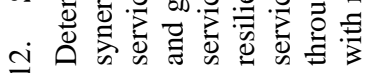
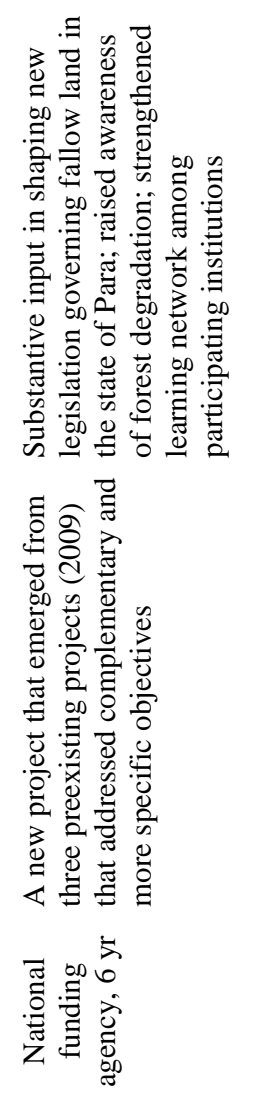

六
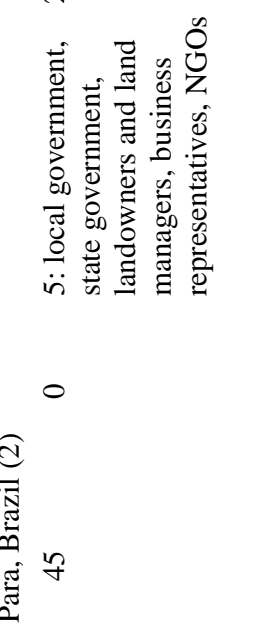

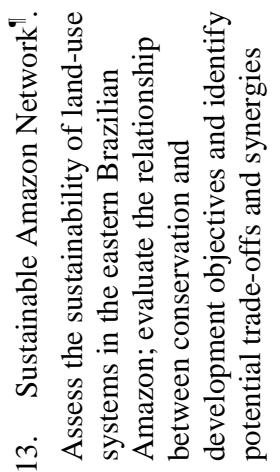

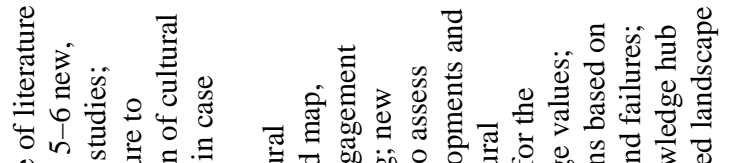

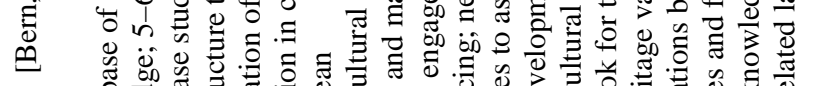

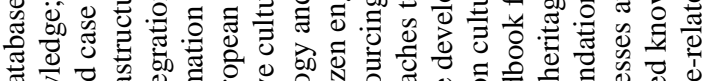

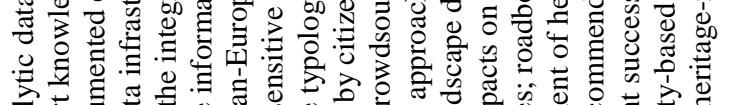

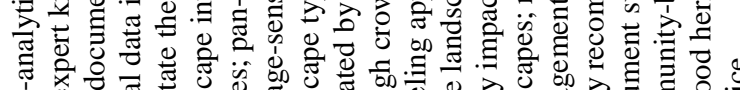

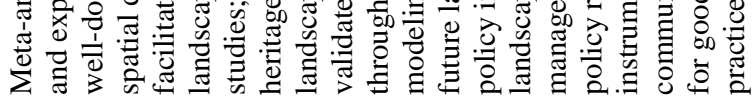

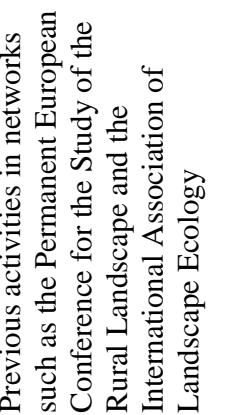

चี

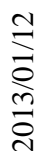

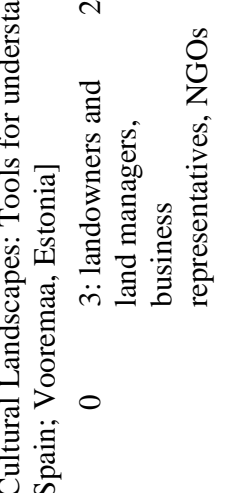

$\Xi$.ंत्र

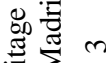

可

苋造

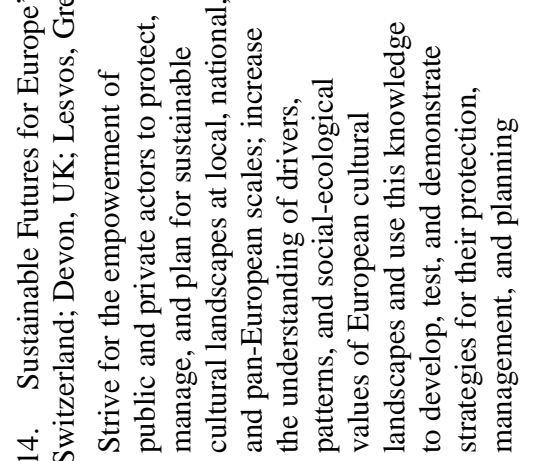



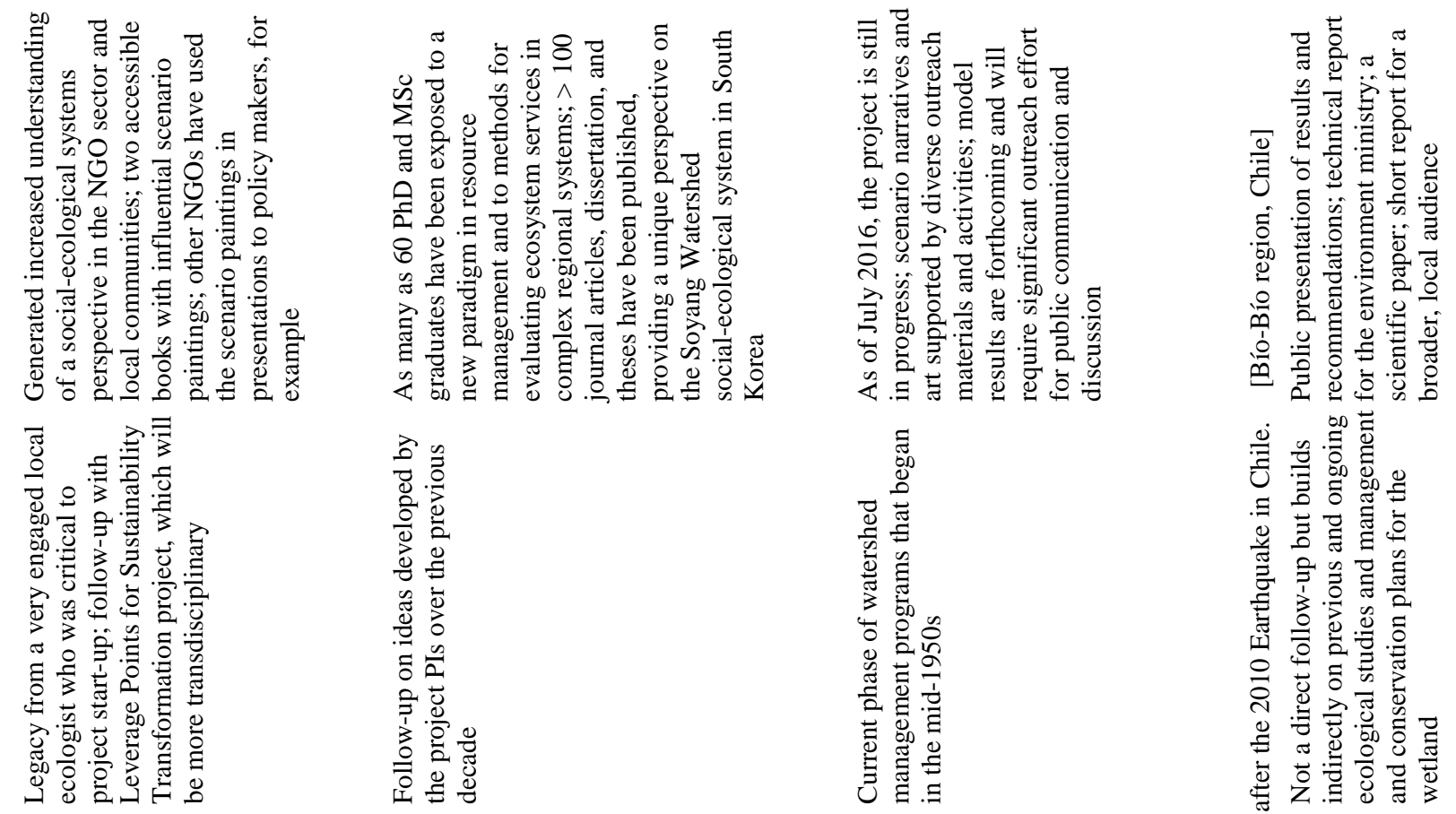

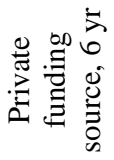
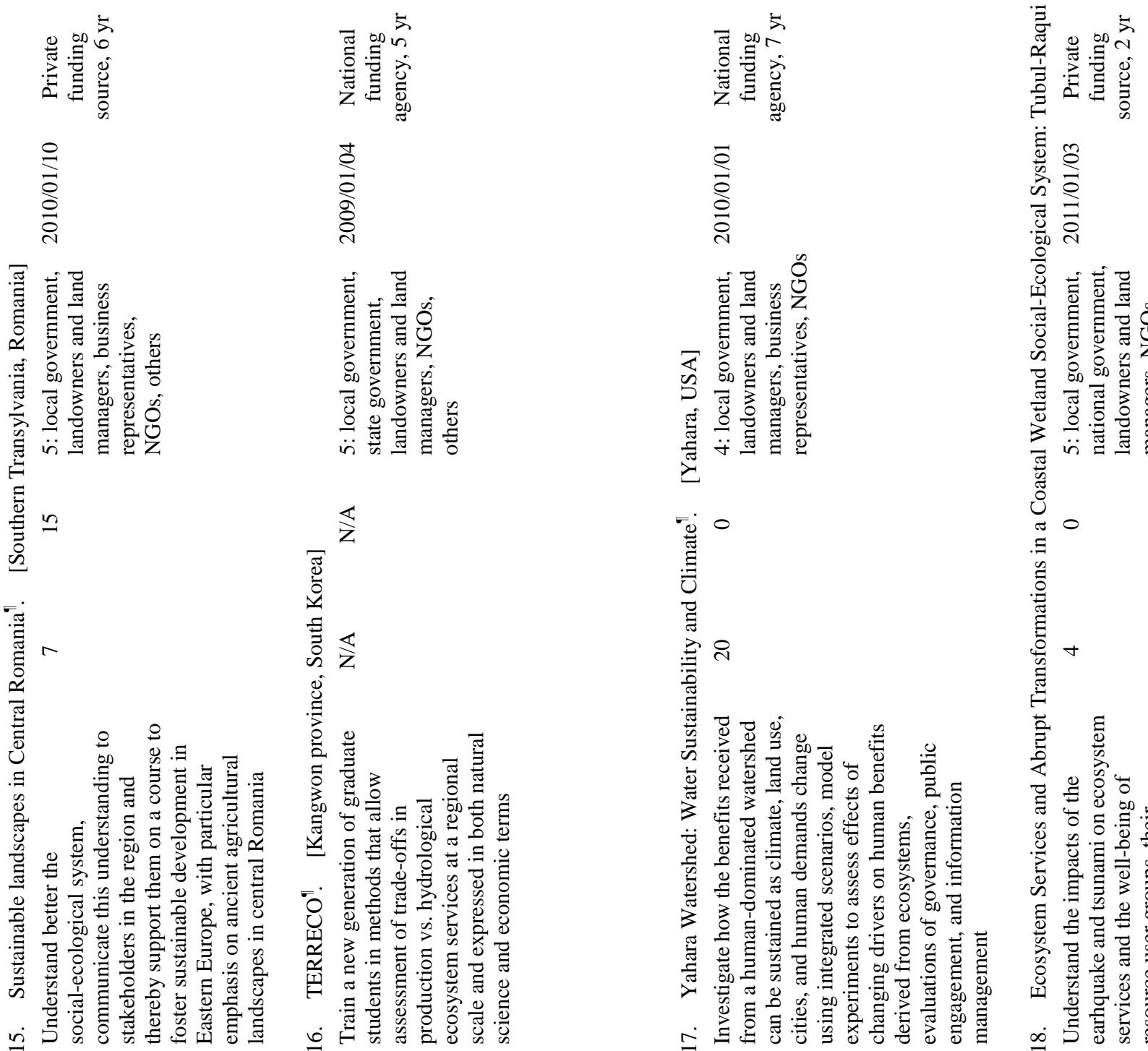

¿্ণ
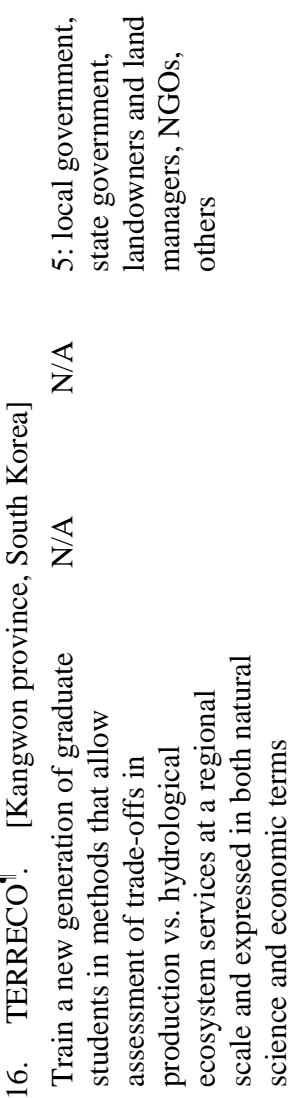
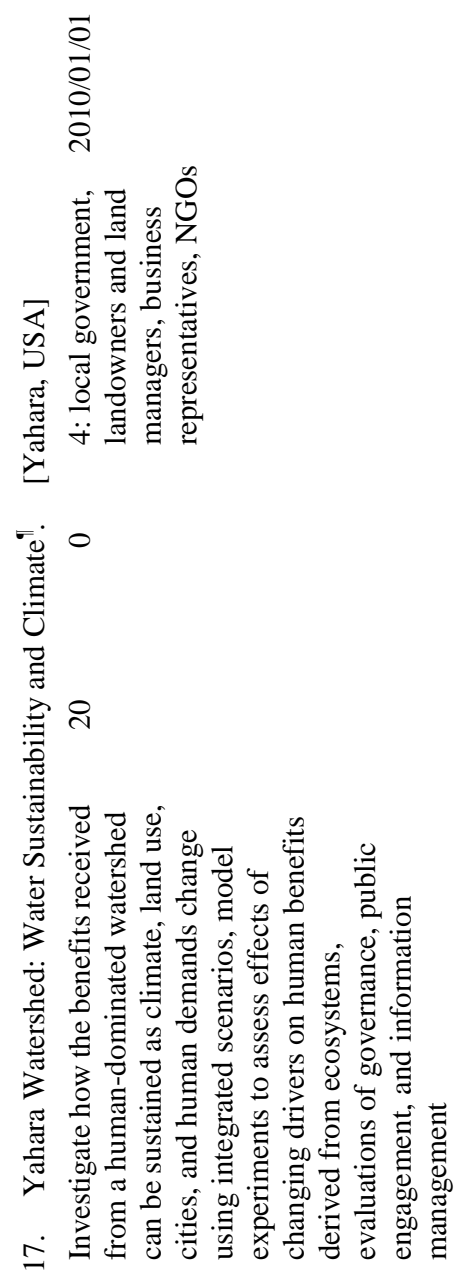

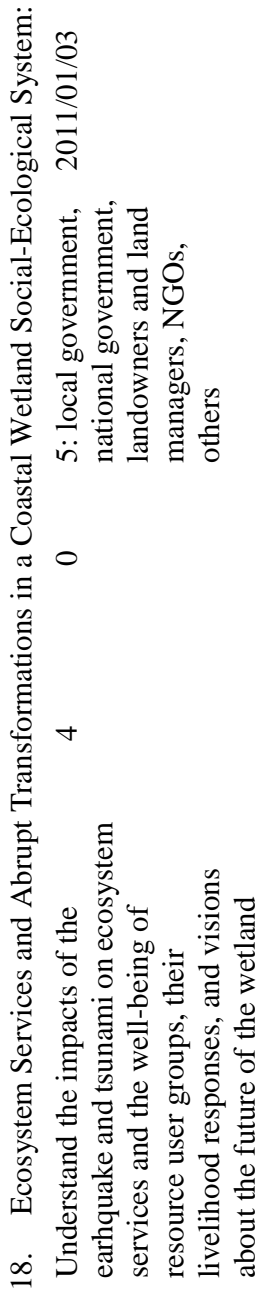



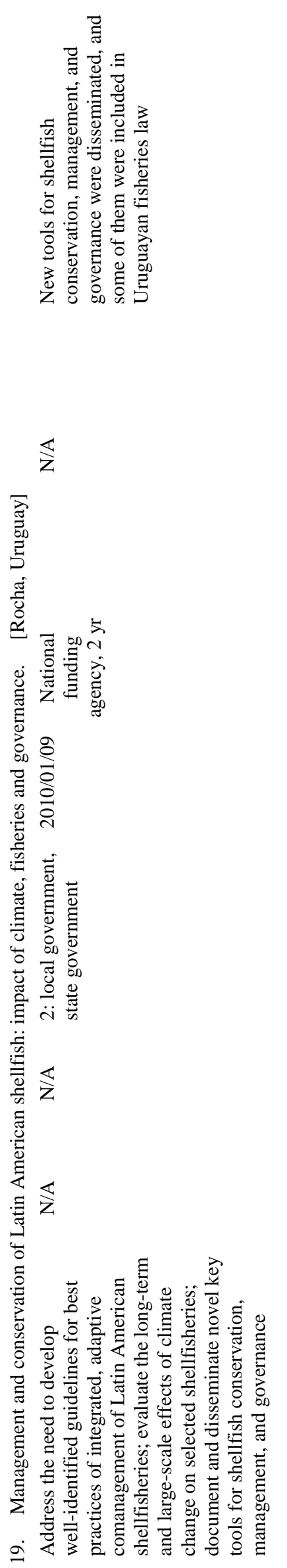
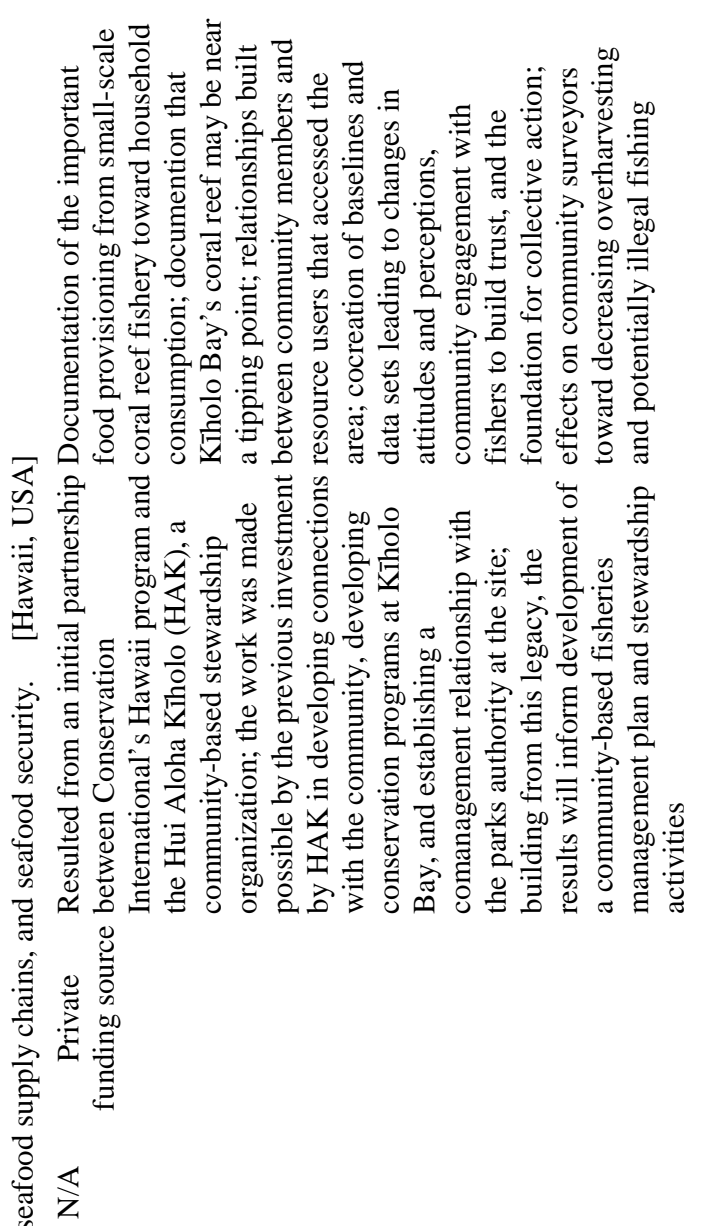

푝
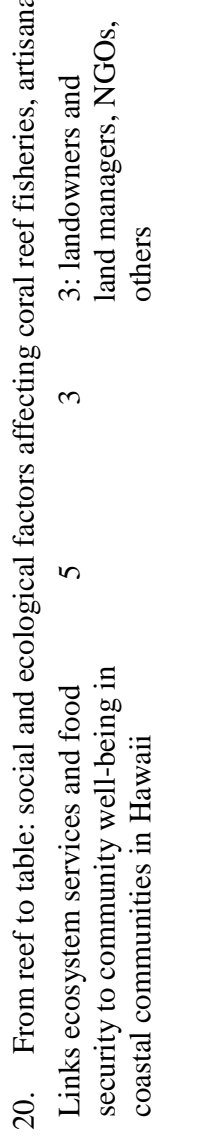
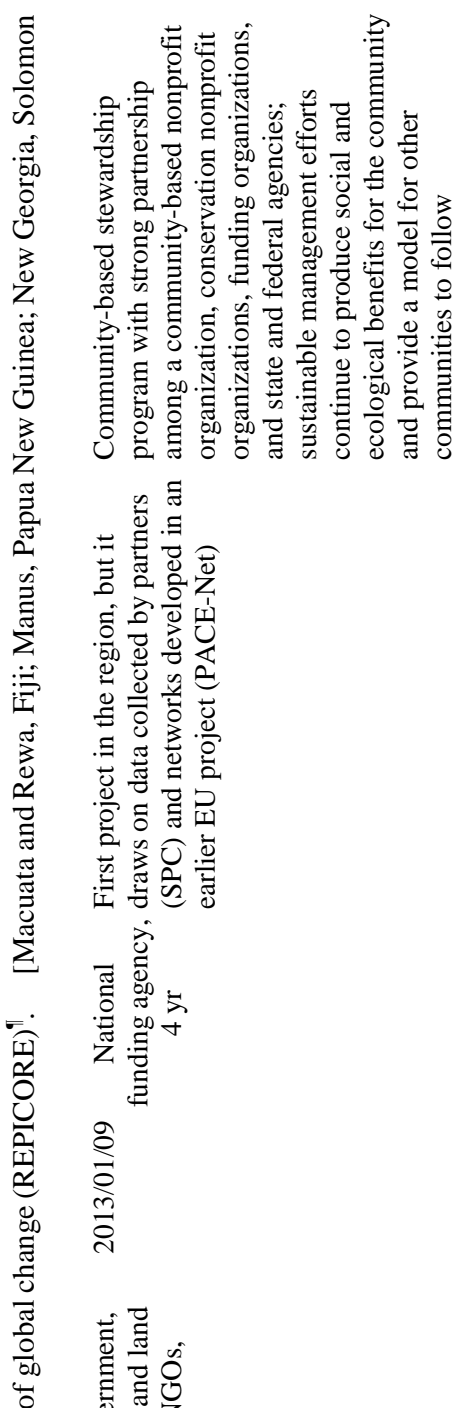

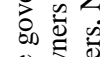

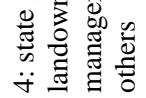

。

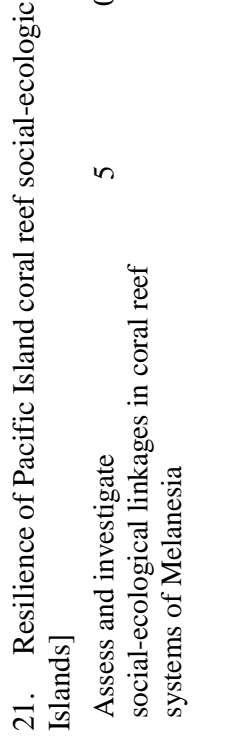




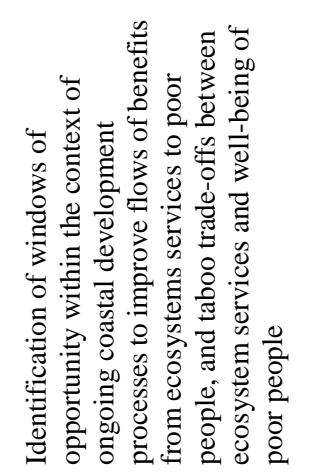

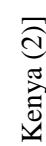

窟艺

톨

ฮิ

韋

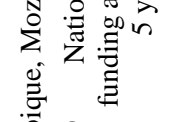

हैํํำ



告

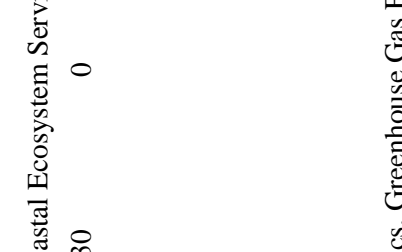

路

छี

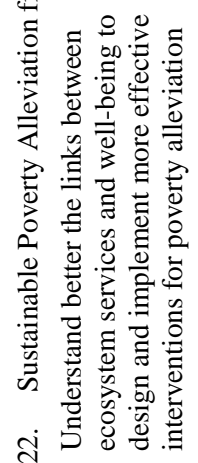

0
0
0
0
0
0
0
0
0
0

䨌

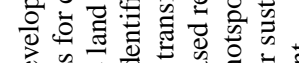

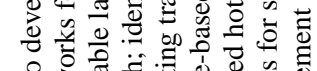

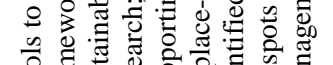

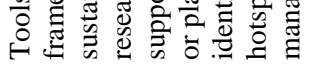

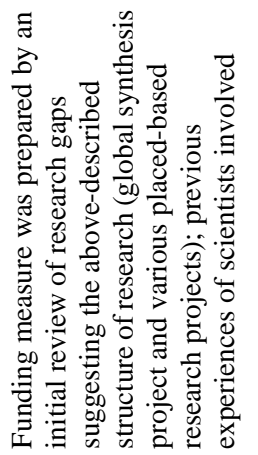

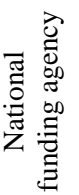

ஓ

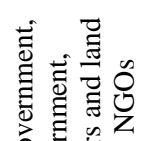

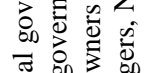

可品

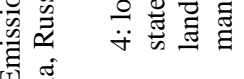

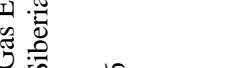

जू

要

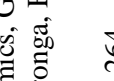

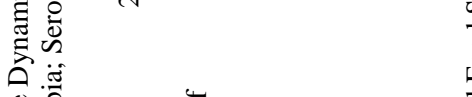

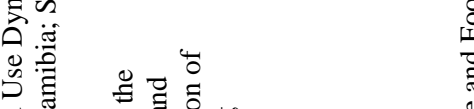

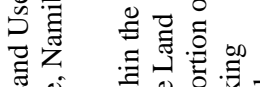

窇言

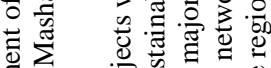

言

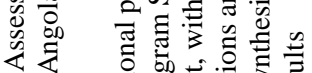

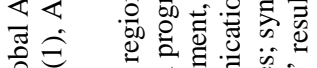

응 을

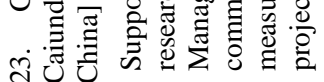
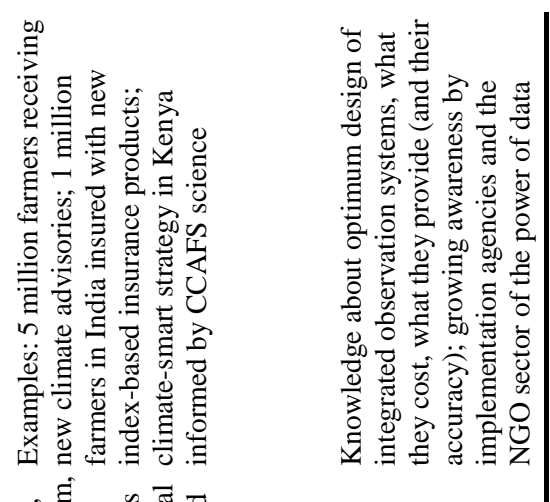

함

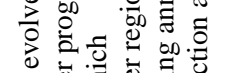

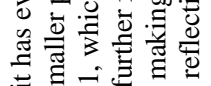

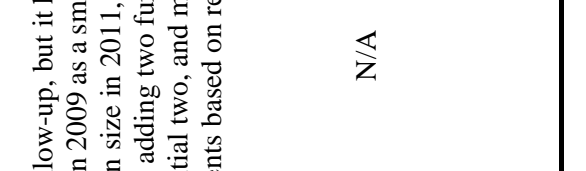

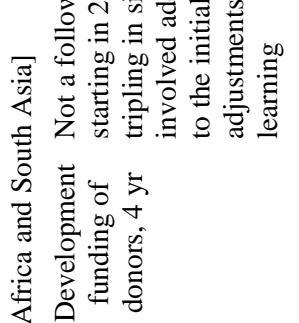

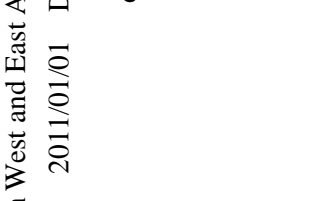

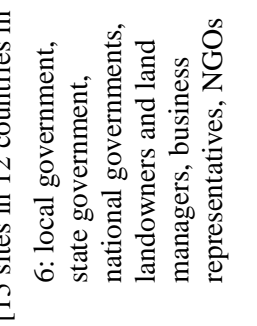

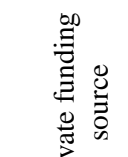

:

울

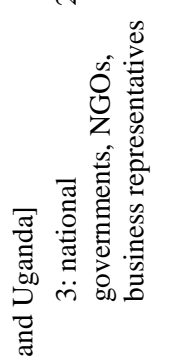

葟。

?

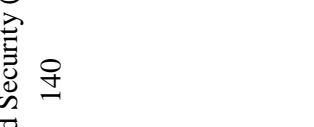

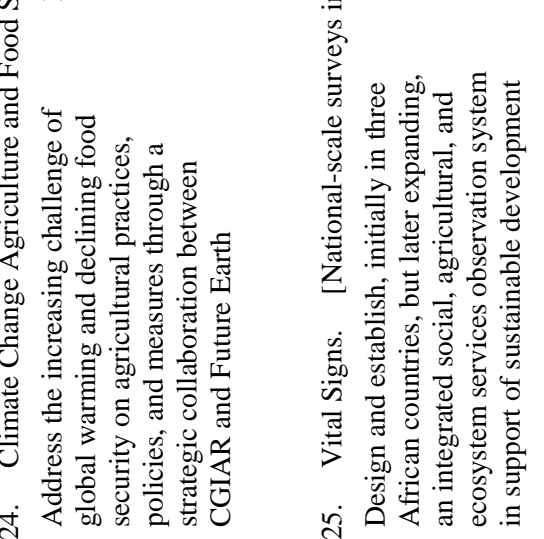

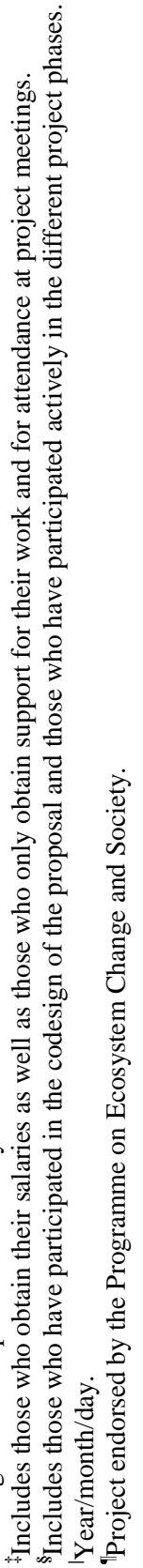


European Union Framework Programme 7) have been the major source of funding in the case of three projects, whereas private organizations, NGOs, or development agencies were the main form of financial support for the remaining five projects. Most of the surveyed projects are ongoing (except for five projects). The funding period varied greatly, with some projects having secured funding for $7 \mathrm{yr}$, whereas others did so only for $2 \mathrm{yr}$.

Fig. 3. Network diagram showing the 25 projects linked by common keywords based on a semantic analysis of the project abstracts. Colored clusters indicate convergent projects by shared keyword-ngrams. The six most common keywords in each group are shown in bars under the cluster's title; numbers in the bars indicate the number of times the keyword occurred in that group; the size of bars indicates the importance, determined as local frequency $\times$ global frequency (i.e., the proportion in the group [xy/number of nodes in the group] times the fraction relative to the population $[\mathrm{xy} / \mathrm{xyN}])$. In other words, a tag is important if it is locally common and otherwise rare. For example, if "services" is common in the group and is also globally common, then it does not distinguish the group very well. Node size indicates the level of centrality within clusters. There are three bridging projects $(9,15$, and 25) that are more similar to projects of the other clusters than the rest of the projects in their own cluster.

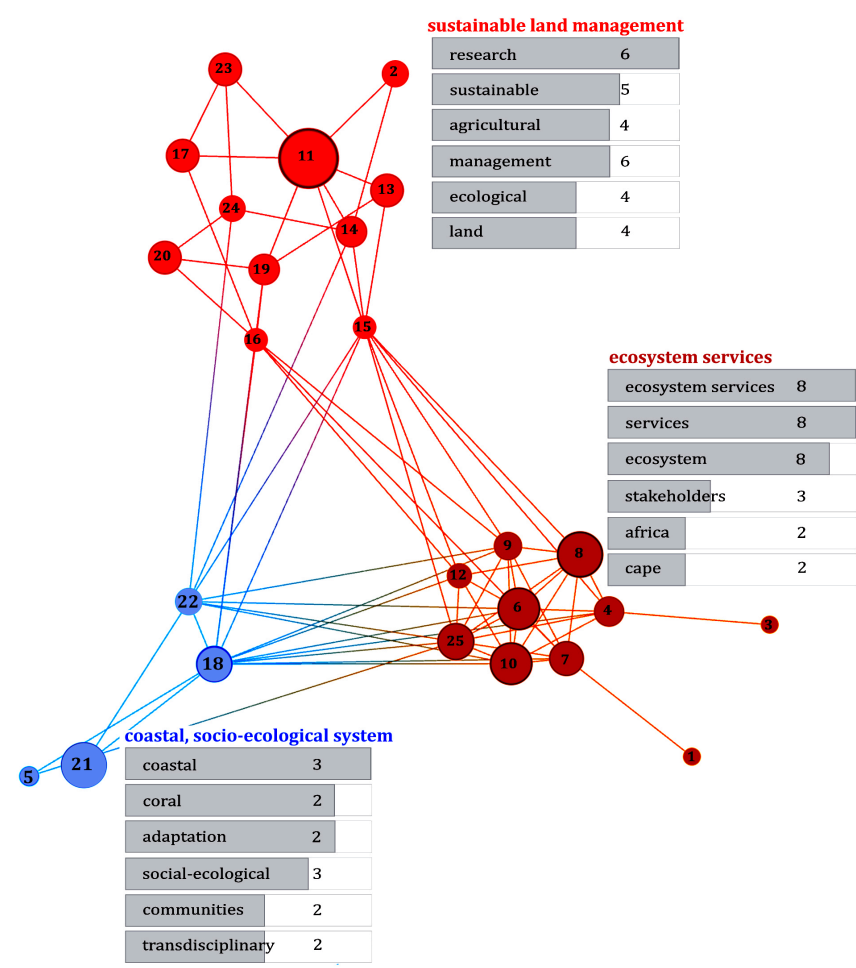

Stakeholders were directly involved in the funding and design of only 9 of the 25 projects. However, interactions in 22 projects occurred with a range of stakeholders, including local, state, and national government; landowners and land managers; business representatives; and NGOs.
Beyond academic products such as papers and student theses that advance knowledge on the SESs studied as well as the theory, 13 of the 25 projects have produced a range of other outputs. These include communications to nonscientific audiences (using other formats of dissemination such as popular media, books, photos, or paintings), raising awareness, increasing communication among stakeholders and participation of stakeholders in research, as well as the identification of alternative future scenarios and the design and implementation of more desirable management practices, legislation, and governance arrangements.

What contributes to the success of place-based social-ecological sustainability research?

The survey revealed a number of attributes, desirable aspects, and enabling factors that were consistently mentioned across the analyzed features in the survey. Other factors were specific to a particular feature (Fig. 4). Examples of such responses are provided (Table 2).

Fig. 4. Features, desirable aspects, and enabling factors that contribute to the success of place-based social-ecological research. Crosscutting features are in the center. Different types of features related to this type of research are outside the circle.

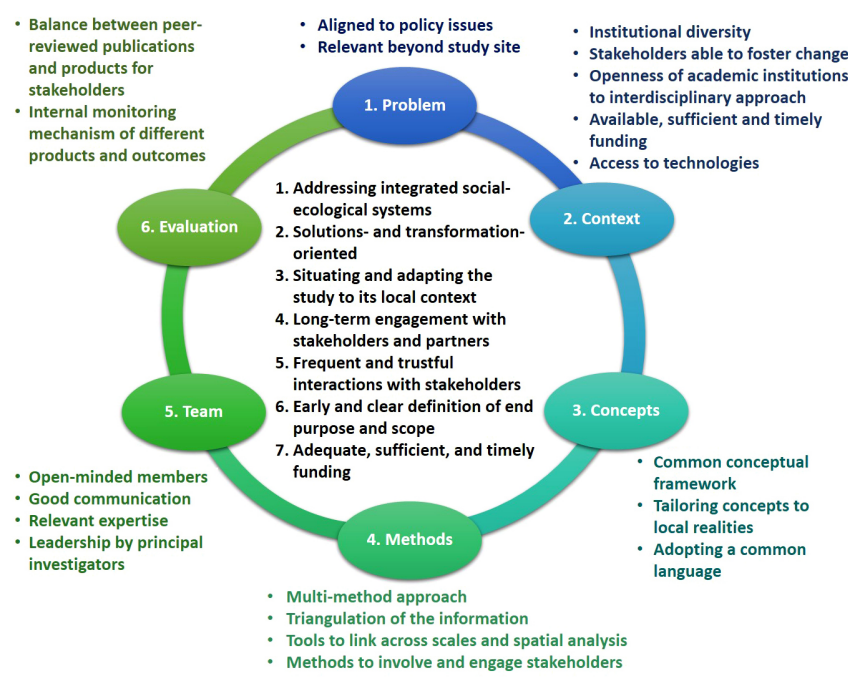

Crosscutting attributes

The explicit recognition of landscapes and seascapes as SESS that comprise interacting social, economic, and ecological elements was recurrently mentioned as a crosscutting feature that enabled PBSESR. In fact, a striking finding was that the different dimensions of research foci were considered, on average, to be similarly important, with almost identical rankings of importance between biodiversity, ecological processes, biophysical conditions, economic activities, human well-being, governance arrangements, and informal institutions. Similarly, respondents repeatedly highlighted the need to address multiple spatial and temporal scales and social levels of organization (including both formal and informal institutions). Another crosscutting theme emphasized was the solutions- and transformation-oriented type of research in which a transition toward sustainability was commonly suggested as a characteristic of successful PBSESR. 
Table 2. Examples of features, desirable aspects of features, and enabling factors that contribute to the success of place-based socialecological sustainability research based on the surveyed projects. Literal quotations are from interviews; other points are summaries of equivalent responses among projects.

\begin{tabular}{|c|c|c|}
\hline $\begin{array}{l}\text { Features, desirable aspects, } \\
\text { and enabling factors }\end{array}$ & Project code $\dagger$ & Examples of survey responses \\
\hline $\begin{array}{l}\text { Addressing integrated social- } \\
\text { ecological systems }\end{array}$ & $6,9,16,20$ & $\begin{array}{l}\text { - "Holistic and comprehensive understanding of the dynanics of ecosystems and } \\
\text { ecosystem services provided and sustainable ecosystem management" } \\
\text { - Taking into account "trade-offs among ecosystem services" } \\
\text { - "Achieving a more realistic view of complex social-ecological systems" } \\
\text { - "Looking at multiple levels of governance, from community to state" }\end{array}$ \\
\hline $\begin{array}{l}\text { Solutions and } \\
\text { transformation oriented }\end{array}$ & $2,18,19,20,21$ & $\begin{array}{l}\text { - Solution oriented } \\
\text { - "Highly policy relevant" } \\
\text { - Includes "history of stakeholder interest in managing and conserving the ecosystem" } \\
\text { - Project developed to assess the social-ecological effects of a tsunami and opportunities } \\
\text { for increased resilience }\end{array}$ \\
\hline $\begin{array}{l}\text { Situating and adapting the } \\
\text { study to its local context }\end{array}$ & $5,7,17,22,11,19,18$ & $\begin{array}{l}\text { "Attaching understanding to place rather than to discipline, i.e., understanding how } \\
\text { what happens in one area (e.g., social relations) affects other areas (e.g., drivers of } \\
\text { change)" } \\
\text { " "Flexibility that allows modification of research questions as research goes on, but not } \\
\text { too much that it becomes too different from the initial research questions" } \\
\text { " "Looking at interventions from social and ecological to institutional context" } \\
\text { " "The contextual features need to be considered in terms of the research questions being } \\
\text { answered" }\end{array}$ \\
\hline $\begin{array}{l}\text { Long-term engagement with } \\
\text { stakeholders and partners }\end{array}$ & $2,9,13,14,15$ & $\begin{array}{l}\text { - "Collaborative development objectives" } \\
\text { - "Includes a network of local groups, interdisciplinary scientific teams, and stakeholders" } \\
\text { - Importance of building on a past legacy of stakeholder-driven research in a region and } \\
\text { the resulting long-standing contacts as an important enabling factor } \\
\text { - "Previous research on political and economic context in combination with good } \\
\text { relations with local stakeholders is relevant" }\end{array}$ \\
\hline $\begin{array}{l}\text { Frequent and trustful } \\
\text { interactions with } \\
\text { stakeholders }\end{array}$ & $3,6,7,8,9,23$ & $\begin{array}{l}\text { - Highlights the process of trust with different stakeholders that has taken place before } \\
\text { starting the project and follows previous research in the study area } \\
\text { "Open attitude of local stakeholders for codesigning outreach products" } \\
\text { - "Communicate the conceptual framework to local stakeholders before applying it" } \\
\text { - Good relations with local stakeholders during the project } \\
\text { - Establishing a communication network }\end{array}$ \\
\hline $\begin{array}{l}\text { Early and clear definition of } \\
\text { end purpose and scope }\end{array}$ & $23,13,25$ & $\begin{array}{l}\text { - "Focus on focal questions and thematic clustering of research projects" } \\
\text { - Delivering scientific syntheses, general patterns toward solutions, and final products } \\
\text { beyond the duration of the project } \\
\text { - Having a clear "theory of change" } \\
\text { - Clearly distinguishing between outputs and outcomes }\end{array}$ \\
\hline $\begin{array}{l}\text { Adequate, sufficient, and } \\
\text { timely funding }\end{array}$ & 9 & $\begin{array}{l}\text { - Funding institution is able to give enough freedom to researchers to identify the research } \\
\text { questions }\end{array}$ \\
\hline
\end{tabular}

$\dagger$ See Table 1 for individual project details.

Respondents insisted that projects should be solutions oriented and focus on the development of actual interventions, thus going beyond basic knowledge generation. This characteristic entails situating and aligning a project within the appropriate local and regional context, including the social and political setting. This could result through building on long-standing projects in the same area or careful participatory research.

The need for establishing tight links with stakeholders was frequently mentioned as an important crosscutting feature to ensure the success of PBSESR projects. These relationships were deemed to be based on trusted partnerships, underpinned by consistent dialogue, and to be long-standing in nature. The actual nature of stakeholder involvement in the projects ranged from interactions between the research team and stakeholders in preparatory consultations to the codesign of research and coimplementation of practices and policies. Particular emphasis was placed on the desirability of giving voice to the less powerful stakeholders and the importance of paying careful attention to the often highly imbalanced power relations between different stakeholders. Many respondents viewed an iterative refinement of research questions, in collaboration with stakeholders and during the evolution of the project, as a desirable characteristic of research, and highlighted participatory methods as being essential to achieving this and in building trusted partnerships. Another highly related crosscutting theme that was often mentioned was the exploration of the perspectives of the different types of stakeholders. For the sake of engaging nonacademic stakeholders in the research, respondents also highlighted the importance of participatory processes. Such participatory processes should consistently engage team members with diverse backgrounds and areas of expertise, as well as local stakeholders and institutions. Further, the importance of epistemological agility (the ability to work across multiple knowledge domains) among team members and the use of multimethod approaches were both highlighted by several respondents. These skills and 
Table 3. Examples of features, undesirable aspects of features, and obstacles that hinder the success of place-based social-ecological sustainability research based on the surveyed projects. Literal quotations are from interviews; other points are summaries elaborated to describe and clump equivalent responses among projects.

\begin{tabular}{|c|c|c|}
\hline $\begin{array}{l}\text { Features, undesirable } \\
\text { aspects, and obstacles }\end{array}$ & Project code ${ }^{\dagger}$ & Examples \\
\hline $\begin{array}{l}\text { Complexities inherent to } \\
\text { social-ecological systems }\end{array}$ & $6,9,7,16,20$ & $\begin{array}{l}\text { - "Design can be time consuming and move project away from interesting research } \\
\text { questions" } \\
\text { - "Should be more than one social science element within a big project" } \\
\text { - Perhaps consider integration as a separate project, rather than leave it all up to a single } \\
\text { social scientist } \\
\text { - Mismatch between scales of evaluation for ecological and socioeconomic processes }\end{array}$ \\
\hline $\begin{array}{l}\text { Imposition of } \\
\text { epistemologies and methods }\end{array}$ & $2,18,19,20,21,23$ & $\begin{array}{l}\text { - "Culturally inappropriate management styles" } \\
\text { - "An 'elite' captures the monitoring system... that determines the criteria for success and } \\
\text { has a large say in evaluating it" }\end{array}$ \\
\hline $\begin{array}{l}\text { Long-term research and } \\
\text { long initiation process }\end{array}$ & $2,9,12,13,14,15$ & $\begin{array}{l}\text { - Massive amount of time and organizational needs } \\
\text { - Not enough time to go in depth into emerging research questions } \\
\text { - Start-up time is slow and bumpy, and funding is usually short term, e.g., } 3 \mathrm{yr} \\
\text { - "Too many stakeholders can bring significant complexity and transaction costs" } \\
\text { - "Significant transaction costs in engaging with multiple conceptual frameworks and } \\
\text { approaches" }\end{array}$ \\
\hline $\begin{array}{l}\text { Conflicts among } \\
\text { stakeholders }\end{array}$ & $5,7,17,22,11,19,18$ & $\begin{array}{l}\text { - "Raising unrealistic expectations among stakeholders who introduce their own agenda" } \\
\text { - Not open to exchanges with stakeholders }\end{array}$ \\
\hline $\begin{array}{l}\text { Power asymmetries in } \\
\text { research team and among } \\
\text { stakeholders }\end{array}$ & $3,6,7,8,9,23$ & $\begin{array}{l}\text { - "Disrespectful attitude toward other knowledge types (local ecological knowledge or } \\
\text { traditional knowledge)" } \\
\text { - "Desire for strong, centralized, hierarchical control by lead PI" } \\
\text { - "Different expectations regarding outputs and outcomes in mixed teams" }\end{array}$ \\
\hline $\begin{array}{l}\text { Difficulty in demonstrating } \\
\text { products }\end{array}$ & $12,13,14$ & $\begin{array}{l}\text { - Huge transaction costs; few organizations fund this work } \\
\text { - Policy-relevant goals can constrain research trajectory }\end{array}$ \\
\hline
\end{tabular}

See Table 1 for individual project details.

methods allow a range of scales and topics to be explored and integrated.

Finally, an early and clear definition of the purpose and scope of the project was deemed critical. The definition of project success was also reported to be critical for identifying the roles of different team members, as well as ownership of its different types of products and outcomes. Adequate funding was considered critical to attain these goals.

\section{Specific attributes for each of the features}

Concerning the process of problem orientation, respondents highlighted the need to align projects to focal policy issues and the importance of being able to compare results with other study regions.

Governance and institutional settings emerged as important contextual features to foster both research and management solutions. Although some survey respondents argued for the need to include sites with a diversity of institutional settings and governance aspects, others considered that a stable ("good governance") institutional setting was a precondition for effective and long-term PBSESR. Respondents also highlighted specific features related to the academic and funding contexts, such as availability of funding for and institutional openness to transdisciplinary social-ecological research, that were deemed important for PBSESR to thrive.

The understanding of the particular SES, the key issues at stake, and the opportunities for interventions toward solutions were considered to rely heavily on the adoption of an explicit visual conceptual framework. Respondents considered that this framework could describe the key phenomena being studied only if project participants invest sufficient time in its codesign. In further considering the factors that can enable a strong and constructive conceptual basis for PBSESR, respondents also underscored the importance of adopting a common language for describing the study system and any insights that emerge from the research process.

Given that the understanding of the whole system and the particular issues at stake is critical, methodological features recognized as important for PBSESR were mainly related to those that allow linking different disciplines and knowledge systems (i. e., scientific and local knowledge). These relate to the use of multiple methods for data collection (e.g., individual and deliberative techniques), the analysis of both qualitative and quantitative data, approaches for triangulating different information sources, analysis across multiple scales and levels of organization, and diverse ways of visualizing research results.

The composition of the team was deemed critical. A diversity of participants, including several thematic dimensions as well as different types of knowledge, was considered desirable, as well as the direct or indirect incorporation of stakeholders. Functional teams were considered to rely on important elements such as including a diversity of team members, open mindedness, trusting collaborative relationships, and communication. Diversity was seen as desirable mostly with regard to disciplinary background, but also seniority and nationality. Openness and interest in different disciplines and perspectives and a willingness to communicate and adapt individual agendas were considered important dimensions of a constructive research attitude. 
Because PBSESR is not only about knowledge generation but about fostering practical solutions, the products of this type of research consistently included items beyond traditional academic products of papers, reports, and research presentations. The understanding and use of research findings by stakeholders as well as sufficient time to allow meaningful engagement with nonresearch audiences and feedback from stakeholders on the strengths and weaknesses of the project were deemed important. A wide range of communication with stakeholders and production of outreach materials such as posters, flyers, videos, postcards, blogs, and tweets, i.e., explicitly geared to what stakeholders could use, was frequently mentioned.

The concept of transformations was deemed to be critical to PBSESR, beyond tangible products and in the context of shortto long-term outcomes. Transformations were conceived of in the way that stakeholders perceive key issues and make decisions, in the capacities of the team members to address key issues, and in the opportunities to implement more sustainable pathways within the SES. Evidence of such outcomes is often difficult to gather, but one project pointed to the successful employment of an administrator that coordinates the collection of evidence of impact and outputs.

\section{What features can hinder the success of place-based social- ecological sustainability research?}

The majority of the attributes, undesirable aspects, and factors that constrain successful PBSESR, as highlighted by respondents, were the opposite of desirable aspects or enabling factors. We thus focus on some of the novel identified undesirable aspects and obstacles (Fig. 5, Table 3).

Fig. 5. Features, undesirable aspects, and obstacles that hinder the success of place-based social-ecological research.

Crosscutting features are in the center. Different types of features related to this type of research are outside the circle.

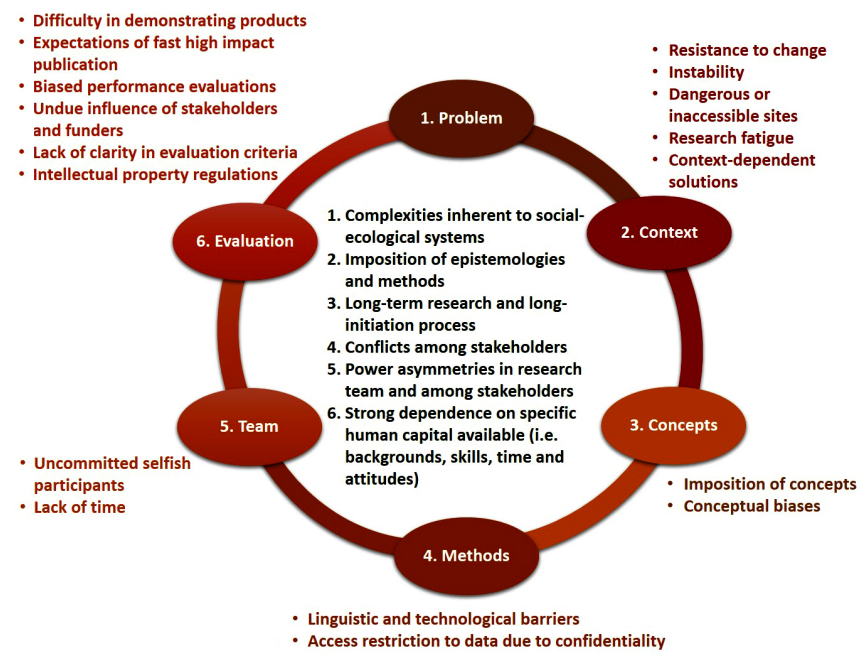

A key crosscutting obstacle to the success of PBSESR that was reported consistently by survey respondents was the complexity inherent in a system-wide social-ecological approach. The need for addressing multiple scales in space and time as well as multiple levels of social and institutional organization and the use of multiple methods present enormous challenges compared to more conventional disciplinary research. The successful understanding of complex SESs and the search for solutions can be constrained by biases that can emerge from insufficient attention given to developing the conceptual basis of the research program with all the team members. The imposition of epistemologies, concepts, or methods inappropriate to the local context, end users, or team members with different backgrounds was highlighted as an important obstacle. These impositions were identified as resulting from power relations among team members and from a lack of meaningful codesign with all the team members of the project.

The inherent complexity of PBSESR projects demands a long initiation period to build an effective team, appropriately align the research to the local context, and ensure that there is adequate opportunity for receiving and processing feedback from research users. These investments can often be viewed as opportunity costs to producing conventional research outputs, commonly resulting in tensions and competing priorities within and between team members.

The complexities of interpersonal relationships among stakeholders, among research team members, and between stakeholders and researchers constitute one major obstacle to the success of PBSESR. Conflicts among stakeholders, particularly those derived from a strong imbalance in power between different stakeholder groups, were consistently mentioned as disrupting attempts to foster a fair and meaningful participatory process. Similarly, conflicts among research team members and competing agendas were also reported as important obstacles to PBSESR, including a lack of commitment to the project and power asymmetries within the team because of domination by more senior researchers or those from the global North. Regarding the relationship between researchers and stakeholders, inadequate communication skills of researchers, research fatigue among respondents of social surveys, and frustration of stakeholders regarding the slow report-back time of research findings were also cited as factors that can inhibit PBSESR. Lack of time to build and nurture the relationships and address issues that can be managed was consistently considered an important obstacle.

Obstacles to the implementation of multiple methods to assess SESs included linguistic barriers between researchers and stakeholders. In addition, data acquisition was reported to be potentially constrained by inadequate access to or understanding of technological tools by stakeholders. The lack of relevant data and the existence of restrictions of access to such data because of confidentiality, legal or political dispositions, or to threats to the security of involved stakeholders were considered important obstacles.

These challenges raised by the nature of PBSESR converge into a major issue frequently mentioned by respondents: the difficulty in demonstrating the products and outcomes of this type of research. While projects experience pressure for fast and highimpact evaluations, they also aim at solutions that can be coconstructed with actors over the medium to long term. Mismatches between the expectations of funders, academic institutions, and stakeholders were often mentioned as an obstacle to PBSESR, as well as a persistent lack of clarity in evaluation criteria. Unrealistic pressure on researchers to become 
agents of change or to provide generalized one-size-fits-all solutions were also considered undesirable features.

\section{Current self-assessed performance of the surveyed projects}

In general, participants considered that their own projects were performing better for team and context features than for methods, evaluation, and problem features. With respect to problem features, participation of stakeholders was rated more favorably than a focus on solutions. In the case of team features, potential improvements were identified in stakeholder integration, communications, team size, adaptability of team members, and interdisciplinarity. Researchers perceived their performance in relation to scientific outputs to be generally good or excellent. However, the spheres in which performance was ranked as being poor were mostly related to outreach and communicating research to stakeholders, policy makers, and the broader public. In addition, organizing training courses and workshops were rated poorly.

\section{DISCUSSION}

Our study confirms a number of findings, both in early (Shaner et al. 1982, Nicolescu 1996, Sharma et al. 1996, Borda 2007, De Sousa Santos 2009) and more recent (Kueffer et al. 2012, Lang et al. 2012, Brandt et al. 2013, Mauser et al. 2013, Ruppert-Winkel et al. 2015, Scholz and Steiner 2015b, Turner et al. 2016) publications, on the particular challenges and opportunities faced by sustainability science. However, the perspective provided by the grouping of PECS-related projects offers a number of distinct contributions. This work differs from previous theoretical explorations (Lang et al. 2012, Miller 2013, Scholz and Steiner 2015a), systematic literature reviews (e.g., Yarime et al. 2010, Bettencourt and Kaur 2011, Brandt et al. 2013), and calls for action (Borda 2007, De Sousa Santos 2009) in providing a firsthand analysis of insights gained from project practitioners involved in the dedicated learning network of PBSESR, that is, PECS. The insights gained here closely mirror those obtained from a recently published synthesis on the evolution of global environmental projects, including other projects now included in Future Earth beyond PECS (Turner et al. 2016).

The emphasis on place, which is a particular characteristic of PECS, allows for the identification of the specific relationships among agents, processes, and resources at different temporal and spatial scales that together help shape a particular region (Carpenter et al. 2012). Place rarely offers an explicit focus of approaches that seek to test specific hypotheses or develop understanding (Fischer et al. 2014). The focus on place allows for the development of trusted relationships with key stakeholders, which in turn provides a basis for more meaningful processes of knowledge transfer. Moreover, the insights gained here are informed by a global network of researchers that have experienced and are based in a wide range of social-ecological contexts and places.

High stakeholder engagement in the development of the research project has been found to be key to PBSESR in three papers of this Special Feature in Ecology and Society that include many PECS-related projects (Cundill et al. 2015, Mitchell et al. 2015, Oteros-Rozas et al. 2015). Although most of the projects assessed here reported interactions with stakeholders, different degrees of participation of stakeholders in project design were found. The projects assessed here ranged from those based on coproduction of knowledge, through those based on codesign and coimplementation of the research, to those based on coimplementation of practices and policies. The limited proportion of projects that were developed in tight collaboration with local stakeholders reflects an important lag in the reality of PBSESR relative to aspirations.

The PECS-related projects assessed here cover the different approaches of transdisciplinary sustainability science (Miller 2013): the knowledge-first approach as well as the processoriented approach. The PECS-related projects aimed at generating different types of knowledge (i.e., systems, target, and transformative knowledge; Hirsch Hadorn et al. 2006, Brandt et al. 2013, Brink et al. 2016) and research questions, including: (1) observations of the key features and drivers of a SES (e.g., projects 6,10 , and 12), (2) scope of action and problem-solving measures to identify best management practices (e.g., projects 14,15 , and 17), and (3) practical implications for identifying transitions toward alternative pathways.

\section{Lessons for fostering international collaborations of place-based research}

PECS provides a platform for contributing toward global sustainability by fostering comparisons among sites; sharing methods, hypotheses, and conceptual frameworks; and sharing strategies for understanding the connections between the local and the global (Mauser et al. 2013, Fischer et al. 2014, Liu et al. 2015). However, the results of this survey emphasize the need to tailor PBSESR, and general conceptual and methodological frameworks and stakeholder dialogue processes, to specific socialecological contexts (Lang et al. 2012, Martín-López and Montes 2015). Similarly, the survey also emphasizes the risks of imposing particular epistemologies or methods on a diverse research team, while also highlighting the benefits of having access to a diversity of methodological approaches and the insights that can be gained through efforts to uncover local expertise and perspectives (Vessuri 2014).

The challenges posed by power imbalances among researchers in terms of their different sources of knowledge, funding opportunities, and modes of communication have been highlighted as problematic by many international research initiatives (Mauser et al. 2013, Scholz and Steiner 2015a). Respondents to our survey emphasized the need to acknowledge the strengths of each of the partners, and in particular, the need to give voice to and balance international, regional, and local perspectives. Place-based research networks such as PECS can facilitate much-needed international collaborations in which place-based studies and researchers from the global South would be better represented.

\section{Accelerating progress toward inter- and transdisciplinary integration}

Integration across disciplines relies on the effective functioning of interdisciplinary teams, yet achieving this is not trivial. In particular, developing a shared understanding and appreciation of the value of different perspectives requires time, both for individuals and groups (Giri 2002, Evely et al. 2008, Miller et al. 2008, Kueffer et al. 2012). Moreover, engendering effective interdisciplinary research teams requires the definition of common objectives and establishment of trusted relationships 
and accessible modes of communication, all of which are processes that require long-term engagement (Fraser and Schalley 2009, Thompson 2009, McGreavy et al. 2015). Conflicts among team members regarding commitments to short-term data gathering vs. those committed to fostering long-term changes within the whole SES arise from contrasting perspectives and expectations among team members.

The development of strong and trusted relationships between different researcher and stakeholder groups in a given region can present an even greater and more time-consuming challenge than that facing the development of interdisciplinary research teams. Several of the surveyed projects emphasized the importance of building on a past legacy of stakeholder-driven research in a region and of trusted contacts developed in this research as important enabling if not critical factors to support PBSESR. Indeed, earlier work has pointed out the essential role of longstanding relationships with strategic stakeholders who act as gatekeepers to other local actors (Enengel et al. 2012). Building trusted relationships with diverse local stakeholders relies on researchers' skills beyond the rationality and logic in which many are trained. High levels of emotional intelligence are demanded. Also, the significant time investments needed may often be seen as major opportunity costs relative to more conventional research activities toward producing peer-reviewed publications.

Conflicts and inequitable power relations among stakeholders were highlighted by the survey respondents as particular barriers to the success of PBSESR. The codesign, coproduction of knowledge, and coimplementation of practices imply the integration of multiple stakeholders' beliefs, perceptions, and interests, yet these are often conflicting (Stringer et al. 2006, Lindenfeld et al. 2014, Martín-López and Montes 2015). For example, the integration of indigenous, local, and ecological knowledge into the scientific process has been recognized recently as a crucial feature of understanding diverse SESs, but is also one of the key challenges facing PBSESR (Ifejika Speranza et al. 2010, Bohensky and Maru 2011, Tengö et al. 2014). The integration of different groups and fostering of a unified or coherent voice might be impossible or even undesirable under particular contexts (Voß and Bornemann 2011). How to best articulate differences in values, world-views, and activities is still a key challenge for PBSESR. Open questions remain in terms of how the participation of international team members is locally perceived and who has the legitimacy and capacity to deal with potential conflicts that emerge from the research process.

A common observation made by the projects surveyed is that shared conceptual frameworks can be enormously useful in facilitating communication both within research teams and with local stakeholders. Developing such frameworks often requires time and is an iterative process with the goal of building a common language and understanding. The process of building these frameworks can be as important as the end result, with their development requiring deep communication about the assumptions each stakeholder or scientist brings to the process.

\section{Redefining and measuring the success of place-based social- ecological sustainability research}

The results of our survey offer some clarity as to what may be expected from a successful PBSESR project, i.e., that it can deliver progress in (1) building a strong network of interdisciplinary and transdisciplinary collaborations to foster understanding and knowledge exchange, but also ownership and trust; (2) empowering researchers to generate new scientific knowledge that is of practical utility in informing decision making; and (3) actively helping to move a given SES toward a more sustainable state.

To deliver successfully on these goals, the projects we surveyed reported on the need for progress across a range of short- and long-term objectives. In the short term, this includes the need to identify and establish an adequate multidisciplinary research team before work begins in earnest, as well as collectively to agree on the problem that is being addressed and to avoid the risks involved in setting unrealistic expectations. In the longer term, effort needs to be invested to empower the research and wider stakeholder group to have ownership of the process to help underpin tangible progress in delivering both the insights and the interventions that are needed. To date, very few PBSESR processes have been in existence for more than a decade, limiting the inferences that can be made as to how this process can be made more effective.

From a transdisciplinary perspective, one way of measuring success is to assess how much a given project supported the coproduction of knowledge, codesign of the research question(s), and codissemination of research findings to other researchers and stakeholder groups, as well as coconstruction of transformations (Mauser et al. 2013, Ruckelshaus et al. 2015). More emphasis is needed on the importance of developing an iterative and replicable approach to assessing the relevance and applicability of research for addressing sustainability issues, including the monitoring of interactions with stakeholders and measures for assessing tangible impacts on SESs. Achieving genuine transformations toward more sustainable system states are often advanced as long-term goals of PBSESR. However, the process of evaluating research contributions toward any such a transformation is complex and poorly developed. The process of conceptualizing what a transformation may mean often requires long-term investments in alternative ways of understanding a system, including ways of accounting for and reconciling the diverse and often conflicting views of different stakeholders. This suggests that entirely new ways of evaluating the success of PBSESR need to be developed.

A portfolio of success measures can be used to address the often conflicting interpretations of success as perceived by project participants, funders (academic or private), and stakeholders (Kueffer et al. 2012, Mauser et al. 2013). A project could then give explicit attention to how to navigate the trade-offs among conflicting definitions of success. The portfolio of measures would be aimed at the performance of the project in general, the processes that need to be developed, the achievement of a range of different goals, and the performance of individuals that make up different teams and perform different functions (Lasén 2013). High-impact scientific products can be combined with other kinds of outputs to reach a range of audiences and user groups concerned with the sustainability issues in question (Kueffer et al. 2012). Increasing incentives for collaboration should extend evaluation metrics beyond primary authorship publications or project leadership to multiauthor publications, data-set production, outreach products, educational outputs, mentoring, 
and contributions to actual management policies and practices (Goring et al. 2014). Examples from the projects surveyed here include the production of joint conceptual frameworks to inform understandings, as well as raising awareness and using pictures derived from research to communicate to wider audiences. Networks such as PECS can provide useful information on how to build such a portfolio based on the experiences of research teams across social-ecological, academic, and funding contexts. They could help identify which types of short-, medium-, and long-term products and outcomes are more feasibly attainable and provide more information on the success of PBSESR.

\section{Strategies to foster the success of place-based-social ecological sustainability research}

A careful examination of the survey responses across the PECS network suggests at least five sets of recommendations regarding strategies to foster the success of PBSESR.

1. Allowing enough time for better understanding of socialecological dynamics and the fostering of concrete and trusted engagements with stakeholders. Given that PBSESR is problem and solution oriented, there is often an expectation to contribute useful information to management in the short or medium term. However, the execution of such research necessarily requires long-term time horizons. Because funding is rarely available for longer than standard 3- to 5yr project funding cycles, it is often vital to draw effectively on preexisting connections to the study region and to key stakeholders.

2. Early identification of the role played by different project members and the scope of the project. Early identification of goals, world-views, roles, and limitations was consistently emphasized by respondents to our survey as an important factor of research success. This includes a clear delimitation of the roles played by each of the members of the research team and wider transdisciplinary network, the need to build mutual respect around the complementary roles played by different members and groups in the network, and the importance of not generating unrealistic expectations (Maass and Equihua 2015).

3. Identification of short-, medium-, and long-term products. Strategies that clearly identify a realistic mix of short-, medium-, and long-term products, each of which can be targeted or reshaped to suit different audiences, can reduce pressure on the research team and its individual members to deliver tangible products quickly. Adopting such a tiered approach of deliverables can help navigate the complexities associated with bridging the different approaches to sustainability, the different types of knowledge generated, and the different research questions addressed in sustainability science. The long initiation processes needed to build effective transdisciplinary teams could be shortened through the production of these deliverables.

4. Adoption of internal monitoring processes to evaluate success. Projects can promote internal monitoring systems to evaluate constructively both successes and failures and identify profitable opportunities for learning. Although monitoring of the outcomes of these projects is becoming increasingly common (e.g., Perez et al. 2010), the rigorous application of project management and performance tools such as those used in the business community are extremely rarely used in research projects. Internal monitoring of project development can help create invaluable spaces for collaborative learning (Wittmayer and Schäpke 2014), with creative and safe spaces for critical self-reflection over the roles and contributions forming a key part of this. They can also provide unique information on the dynamics of the project to identify the presence of obstacles (i.e., monitor and manage power inequalities), avoid diversions, and keep product and outcome timelines on track.

5. Pay particular attention to the lessons that can be learned from failure. It is often the case that opportunities for new research and impact emerge more readily from experiences of relative failure than of relative success. This is particularly true given that most of the current premises of transdisciplinary research (Lang et al. 2012) have in fact not been tested. However, there is currently little incentive to record failures, and even less incentive to share such experiences, whereas there is considerable encouragement for projects to evaluate themselves in a way that reflects favorably on their achievements (for example by only evaluating the aspects of the project that have been done well). Promoting the recording and sharing of "failure reports" is only likely to be possible with encouragement (or even an obligation) from funders and academic evaluators, but it is likely to be enormously rewarding.

Addressing challenges within academic institutions and funding agencies to contribute better toward sustainability research and practice

The current structure and criteria for career advancement in scientific institutions often hinders PBSESR. Academic institutions that promote collaboration between researchers (Kueffer et al. 2012) and extend the evaluation metrics beyond primary authorship publications or project leadership to multiauthor publications, data-set production, outreach products, educational outputs, mentoring, and contributions to management should be fostered (Goring et al. 2014). A wider range of target journals, including those more open to sustainability research and those that are locally relevant, needs to be emphasized.

Institutional changes are needed to codevelop new career and project profiles that take into account a wider range of products and outcomes from PBSESR in research evaluation (Fischer et al. 2015). More nuanced evaluation systems are needed that give priority to both locally relevant and slowly evolving outcomes as well as more short-term and highly visible products. Such systems are particularly important for early-career researchers, who are often under particularly intense pressure to produce conventional peer-reviewed papers and yet highly motivated to be involved in PBSESR.

Universities and funding agencies are increasingly under pressure to deliver scientific results that are relevant to societies. New ways to assess the impacts of research on social networks and actual decision-making processes are urgently needed. New ways to engage their faculty in innovative, risky, but timely research, as well as the development of stimuli, are also desirable. Funding is needed to provide sufficient time to build robust transdisciplinary 
research teams that are capable of truly codesigning projects, coproducing knowledge, and coimplementing management strategies in developing collaborative solutions-oriented research. Similarly, enough funding to secure constant communication to refine the project iteratively and to follow long-term transformations is seldom available.

Perhaps above all, new approaches to training and learning are urgently needed. Intensive learning processes have occurred as interdisciplinary and collaborative research has taken place over the past decades (Kueffer et al. 2012), but this is insufficient for addressing the huge scale and scope of the world's sustainability challenges. PBSESR projects offer excellent opportunities for trainees to experience a range of insights across contexts, disciplines, and sectors of society. More efforts should be made in providing new and multiple teaching models that foster complex thinking, stimulate collective learning, and provide an appropriate environment that engages students in reflecting about their own value systems, knowledge systems, and cultural background, as well as the learning processes (König 2015, Vilsmaier and Lang 2015). Research-based learning spaces where students, researchers, and nonacademic stakeholders collaborate and engage in real solutions-oriented projects provide the setting for acquiring competences on how to address sustainability problems collectively (Evans et al. 2015, Wiek and Kay 2015).

\section{CONCLUSIONS}

PBSESR has developed a strong track record of delivering key insights and creating a new generation of sustainability scientists. Such research can be rewarding for researchers because of the ability to work with many different people and to enhance real transitions toward sustainability. However, such research is also immensely challenging because of the complexity of SESs and conflicts with the way scientific funding and careers are currently organized.

We surveyed an emerging research community gathered around the PECS that is focused on PBSESR. We believe that the formation of communities of practice of such researchers, both within and outside of academia, are critical for helping generate new research approaches, new insights from comparative work across study sites and research teams, and practical tools for improving SESs and ways of envisioning solutions to sustainability problems. The community that is being formed by groups such as PECS can also play a vital role in helping catalyze change within academic institutions and funding organizations and foster new training opportunities for fostering PBSESR. It can contribute to designing funding mechanisms that are better suited to the needs and contributions of PBSESR research through improving working conditions and funding schemes for researchers working on the sustainability of SESs.

Efforts to build more sustainable approaches to managing SESs should embrace international as well as locally relevant perspectives through an inclusive approach that actively rewards respectful and collaborative behaviors within the scientific community (Tallis and Lubchenco 2014). We believe that networks such as PECS have a vital role to play in this process.
Responses to this article can be read online at: http://www.ecologyandsociety.org/issues/responses. php/8826

\section{Acknowledgments:}

This paper resulted from workshops held in Stockholm on September 2013, and in Moureze, France, in May 2014, funded by the Programme on Ecosystem Change and Society. We thank all the workshop participants and all the respondents of the pilot and final survey for their valuable insights and all the time spent on it. We also thank Tuyeni Mwampamba, Bárbara Ayala, Lucía Almeida, Nicolás Urbina, and two anonymous reviewers for valuable comments on previous versions of the manuscript.

\section{LITERATURE CITED}

Bennett, E. M., W. Cramer, A. Begossi, G. Cundill, S. Díaz, B. N. Egoh, I. R. Geijzendorffer, C. B. Krug, S. Lavorel, E. Lazos, L. Lebel, B. Martín-López, P. Meyfroidt, H. A. Mooney, J. L. Nel, U. Pascual, K. Payet, N. Pérez Harguindeguy, G. D. Peterson, A.H. Prieur-Richard, B. Reyers, P. Roebeling, R. Seppelt, M. Solan, P. Tschakert, T. Tscharntke, B. L. Turner II, P. H. Verburg, E. F. Viglizzo, P. C. L. White, and G. Woodward. 2015. Linking biodiversity, ecosystem services and human well-being: three challenges for designing research for sustainability. Current Opinion in Environmental Sustainability 14:78-85. http://dx.doi. org/10.1016/j.cosust.2015.03.007

Berkes, F., and C. Folke, editors. 1998. Linking social and ecological systems: management practices and social mechanisms for building resilience. Cambridge University Press, Cambridge, UK.

Bettencourt, L. M. A., and J. Kaur. 2011. Evolution and structure of sustainability science. Proceedings of the National Academy of Sciences 108(49):19540-19545. http://dx.doi.org/10.1073/pnas.1102712108

Bohensky, E. L., and Y. Maru. 2011. Indigenous knowledge, science, and resilience: What have we learned from a decade of international literature on "integration"? Ecology and Society 16 (4):6. [online] URL: http://dx.doi.org/10.5751/es-04342-160406

Borda, O. F. 2007. La investigación-acción en convergencias disciplinarias. Latin American Studies Association Forum 38 (4):17-22. [online] URL: https://lasa.international.pitt.edu/ forum/files/vol38/LASAForum-Vol38-Issue4.pdf

Brandt, P., A. Ernst, F. Gralla, C. Luederitz, D. J. Lang, J. Newig, F. Reinert, D. J. Abson, and H. von Wehrden. 2013. A review of transdisciplinary research in sustainability science. Ecological Economics 92:1-15. http://dx.doi.org/10.1016/j.ecolecon.2013.04.008

Brink, E., T. Aalders, D. Ádám, R. Feller, Y. Henselek, A. Hoffmann, K. Ibe, A. Matthey-Doret, M. Meyer, N. L. Negrut, A.-L. Rau, B. Riewerts, L. von Schuckmann, S. A. Törnros, H. von Wehrden, D. J. Abson, and C. Wamsler. 2016. Cascades of green: a review of ecosystem-based adaptation in urban areas. Global Environmental Change 36:111-123. http://dx.doi. org/10.1016/j.gloenvcha.2015.11.003 
Brondizio, E. S., E. Ostrom, and O. R. Young. 2009. Connectivity and the governance of multilevel social-ecological systems: the role of social capital. Annual Review of Environment and Resources 34:253-278. http://dx.doi.org/10.1146/annurev.environ.020708.100707

Carpenter, S. R., C. Folke, A. Norström, O. Olsson, L. Schultz, B. Agarwal, P. Balvanera, B. Campbell, J. C. Castilla, W. Cramer, R. DeFries, P. Eyzaguirre, T. P. Hughes, S. Polasky, Z. Sanusi, R. Scholes, and M. Spierenburg. 2012. Program on ecosystem change and society: an international research strategy for integrated social-ecological systems. Current Opinion in Environmental Sustainability 4(1):134-138. http://dx.doi.org/10.1016/j.cosust.2012.01.001

Chapin, F. S. III, G. P. Kofainas, and C. Folke, editors. 2009. Principles of ecosystem stewardship: resilience-based natural resource management in a changing world. Springer, New York, New York, USA.

Cheruvelil, K. S., P. A. Soranno, K. C. Weathers, P. C. Hanson, S. J. Goring, C. T. Filstrup, and E. K. Read. 2014. Creating and maintaining high-performing collaborative research teams: the importance of diversity and interpersonal skills. Frontiers in Ecology and the Environment 12(1):31-38. http://dx.doi. org/10.1890/130001

Clark, W. C. 2007. Sustainability science: a room of its own. Proceedings of the National Academy of Sciences 104 (6):1737-1738. http://dx.doi.org/10.1073/pnas.0611291104

Cundill, G., D. J. Roux, and J. N. Parker. 2015. Nurturing communities of practice for transdisciplinary research. Ecology and Society 20(2):22. http://dx.doi.org/10.5751/es-07580-200222

De Sousa Santos, B. 2009. Una epistemología del sur: la reinvención del conocimiento y la emancipación social. Siglo XXI Editores, Mexico City, Mexico, and CLACSO, Buenos Aires, Argentina.

Enengel, B., A. Muhar, M. Penker, B. Freyer, S. Drlik, and F. Ritter. 2012. Co-production of knowledge in transdisciplinary doctoral theses on landscape development - an analysis of actor roles and knowledge types in different research phases. Landscape and Urban Planning 105(1-2):106-117. http://dx.doi.org/10.1016/ j.landurbplan.2011.12.004

Evans, J., R. Jones, A. Karvonen, L. Millard, and J. Wendler. 2015. Living labs and co-production: university campuses as platforms for sustainability science. Current Opinion in Environmental Sustainability 16:1-16. http://dx.doi.org/10.1016/j.cosust.2015.06.005

Evely, A. C., I. Fazey, M. Pinard, and X. Lambin. 2008. The influence of philosophical perspectives in integrative research: a conservation case study in the Cairngorms National Park. Ecology and Society 13(2):52. http://dx.doi.org/10.5751/ es-02679-130252

Fischer, J., T. A. Gardner, E. A. Bennett, P. Balvanera, R. Biggs, S. Carpenter, T. Daw, C. Folke, R. Hill, T. P. Hughes, T. Luthe, M. Maass, M. Meacham, A. V. Norström, G. Peterson, C. Queiroz, R. Seppelt, M. Spierenburg, and J. Tenhunen. 2015. Advancing sustainability through mainstreaming a socialecological systems perspective. Current Opinion in Environmental Sustainability 14:144-149. http://dx.doi.org/10.1016/j.cosust.2015.06.002
Fischer, J., K. Sherren, and J. Hanspach. 2014. Place, case and process: applying ecology to sustainable development. Basic and Applied Ecology 15(3):187-193. http://dx.doi.org/10.1016/j. baae.2013.12.002

Folke, C. 2006. Resilience: the emergence of a perspective for social-ecological systems analyses. Global Environmental Change 16(3):253-267. http://dx.doi.org/10.1016/j.gloenvcha.2006.04.002

Fraser, H., and A. C. Schalley. 2009. Communicating about communication: intercultural competence as a factor in the success of interdisciplinary collaboration. Australian Journal of Linguistics 29(1):135-155. http://dx.doi.org/10.1080/07268600802516418

Giri, A. K. 2002. The calling of a creative transdisciplinarity. Futures 34(1):103-115. http://dx.doi.org/10.1016/S0016-3287(01) $\underline{00038-6}$

Goring, S. J., K. C. Weathers, W. K. Dodds, P. A. Soranno, L. C. Sweet, K. S. Cheruvelil, J. S. Kominoski, J. Rüegg, A. M. Thorn, and R. M. Utz. 2014. Improving the culture of interdisciplinary collaboration in ecology by expanding measures of success. Frontiers in Ecology and the Environment 12(1):39-47. http://dx. doi.org/10.1890/120370

Hirsch Hadorn, G., D. Bradley, C. Pohl, S. Rist, and U. Wiesmann. 2006. Implications of transdisciplinarity for sustainability research. Ecological Economics 60(1):119-128. http://dx.doi.org/10.1016/j.ecolecon.2005.12.002

Hirsch Hadorn, G., H. Hoffmann-Riem, S. Biber-Klemm, W. Grossenbacher-Mansuy, D. Joye, C. Pohl, U. Wiesmann, and E. Zemp, editors. 2008. Handbook of transdisciplinary research. Springer, New York, New York, USA.

ICSU-UNESCO-UNU (International Council of Science, United Nations Educational, Scienific and Cultural Organization, and United Nations University). 2008. Ecosystem change and human well-being: research and monitoring priorities based on the findings of the Millennium Ecosystem Assessment. ICSU, Paris, France.

Ifejika Speranza, C., B. Kiteme, P. Ambenje, U. Wiesmann, and S. Makali. 2010. Indigenous knowledge in climate variability and climate change: insights from droughts in semi-arid areas of former Makueni District, Kenya. Climatic Change 100 (2):295-315. http://dx.doi.org/10.1007/s10584-009-9713-0

König, A. 2015. Changing requisites to universities in the $21 \mathrm{st}$ century: organizing for transformative sustainability science for systemic change. Current Opinion in Environmental Sustainability 16:105-111. http://dx.doi.org/10.1016/j.cosust.2015.08.011

Kueffer, C., E. Underwood, G. Hirsch Hadorn, R. Holderegger, M. Lehning, C. Pohl, M. Schirmer, R. Schwarzenbach, M. Stauffacher, G. Wuelser, and P. Edwards. 2012. Enabling effective problem-oriented research for sustainable development. Ecology and Society 17(4):8. http://dx.doi.org/10.5751/es-05045-170408

Lang, D. J., A. Wiek, M. Bergmann, M. Stauffacher, P. Martens, P. Moll, M. Swilling, and C. J. Thomas. 2012. Transdisciplinary research in sustainability science: practice, principles, and challenges. Sustainability Science 7(S1):25-43. http://dx.doi. org/10.1007/s11625-011-0149-X 
Lasén, A. 2013. On the need for democratic principles to ensure meritocracy in a time of research funding cuts. Papers: Revista de Sociología 98(3):565-571.

Leemans, R. 2016. The lessons learned from shifting from globalchange research programmes to transdisciplinary sustainability science. Current Opinion in Environmental Sustainability 19:103-110. http://dx.doi.org/10.1016/j.cosust.2016.01.001

Lindenfeld, L., H. M. Smith, T. Norton, and N. C. Grecu. 2014. Risk communication and sustainability science: lessons from the field. Sustainability Science 9(2):119-127. http://dx.doi. org/10.1007/s11625-013-0230-8

Liu, J., H. Mooney, V. Hull, S. J. Davis, J. Gaskell, T. Hertel, J. Lubchenco, K. C. Seto, P. Gleick, C. Kremen, and S. Li. 2015. Systems integration for global sustainability. Science 347:1258832. http://dx.doi.org/10.1126/science.1258832

Millennium Ecosystem Assessment. 2005. Ecosystems and human well-being: synthesis. Island Press, Washington, D.C., USA. [online] URL: http://www.millenniumassessment.org/documents/ document.356.aspx.pdf

Maass, M., P. Balvanera, P. Bourgeron, M. Equihua, J. Baudry, J. Dick, M. Forsius, L. Halada, K. Krauze, M. Nakaoka, D. E. Orenstein, T. W. Parr, C. L. Redman, R. Rozzi, M. Santos-Reis, A. M. Swemmer, and A. Vădineanu. 2016. Changes in biodiversity and trade-offs among ecosystem services, stakeholders, and components of well-being: the contribution of the International Long-Term Ecological Research network (ILTER) to Programme on Ecosystem Change and Society (PECS). Ecology and Society 21(3):31. http://dx.doi.org/10.5751/ES-08587-210331

Maass, M., and M. Equihua. 2015. Earth stewardship, socioecosystems, the need for a transdisciplinary approach and the role of the International Long Term Ecological Research Network (ILTER). Pages 217-233 in R. Rozzi, F. S. Chapin III, J. B. Callicott, S. T. A. Pickett, M. E. Power, J. J. Armesto, and R. H. May Jr., editors. Earth stewardship: linking ecology and ethics in theory and practice. Springer, Cham, Switzerland. http://dx.doi. org/10.1007/978-3-319-12133-8 14

Martín-López, B., and C. Montes. 2015. Restoring the human capacity for conserving biodiversity: a social-ecological approach. Sustainability Science 10(4):699-706. http://dx.doi. org/10.1007/s11625-014-0283-3

Mauser, W., G. Klepper, M. Rice, B. S. Schmalzbauer, H. Hackmann, R. Leemans, and H. Moore. 2013. Transdisciplinary global change research: the co-creation of knowledge for sustainability. Current Opinion in Environmental Sustainability 5 (3-4):420-431. http://dx.doi.org/10.1016/j.cosust.2013.07.001

McGreavy, B., L. Lindenfeld, K. Hutchins Bieluch, L. Silka, J. Leahy, and B. Zoellick. 2015. Communication and sustainability science teams as complex systems. Ecology and Society 20(1):2. http://dx.doi.org/10.5751/es-06644-200102

Miller, T. R. 2013. Constructing sustainability science: emerging perspectives and research trajectories. Sustainability Science 8 (2):279-293. http://dx.doi.org/10.1007/s11625-012-0180-6

Miller, T. R., T. D. Baird, C. M. Littlefield, G. Kofinas, F. S. Chapin III, and C. L. Redman. 2008. Epistemological pluralism: reorganizing interdisciplinary research. Ecology and Society 13 (2):46. http://dx.doi.org/10.5751/es-02671-130246

Mitchell, M. G. E., E. M. Bennett, A. Gonzalez, M. J. Lechowicz, J. M. Rhemtulla, J. A. Cardille, K. Vanderheyden, G. PoirierGhys, D. Renard, S. Delmotte, C. H. Albert, B. Rayfield, M. Dumitru, H.-H. Huang, M. Larouche, K. N. Liss, D. Y. Maguire, K. T. Martins, M. Terrado, C. Ziter, L. Taliana, and K. Dancose. 2015. The Montérégie Connection: linking landscapes, biodiversity, and ecosystem services to improve decision making. Ecology and Society 20(4):15. http://dx.doi.org/10.5751/ ES-07927-200415

Mooney, H. 2016. Sustainability science: social-environmental systems (SES) research: how the field has developed and what we have learned for future efforts. Current Opinion in Environmental Sustainability 19:v-xii. http://dx.doi.org/10.1016/j.cosust.2016.05.002

Mooney, H. A., A. Duraiappah, and A. Larigauderie. 2013. Evolution of natural and social science interactions in global change research programs. Proceedings of the National Academy of Sciences 110(S1):3665-3672. http://dx.doi.org/10.1073/ pnas. 1107484110

Mori, K., and A. Christodoulou. 2012. Review of sustainability indices and indicators: towards a new City Sustainability Index (CSI). Environmental Impact Assessment Review 321):94-106. http://dx.doi.org/10.1016/j.eiar.2011.06.001

Nicolescu, B. 1996. La transdisciplinariedad: manifiesto. Multiversidad Mundo Real Edgar Morin, Hermosillo, Mexico.

Norgaard, R. B. 2008. Finding hope in the Millennium Ecosystem Assessment. Conservation Biology 22(4):862-869. http://dx.doi. org/10.1111/j.1523-1739.2008.00922.x

Ostrom, E. 2009. A general framework for analyzing sustainability of social-ecological systems. Science 325:419-422. http://dx.doi.org/10.1126/science. 1172133

Oteros-Rozas, E., B. Martín-López, T. M. Daw, E. L. Bohensky, J. R. A. Butler, R. Hill, J. Martin-Ortega, A. Quinlan, F. Ravera, I. Ruiz-Mallén, M. Thyresson, J. Mistry, I. Palomo, G. D. Peterson, T. Plieninger, K. A. Waylen, D. M. Beach, I. C. Bohnet, M. Hamann, J. Hanspach, K. Hubacek, S. Lavorel, and S. P. Vilardy. 2015. Participatory scenario planning in place-based social-ecological research: insights and experiences from 23 case studies. Ecology and Society 20(4):32. http://dx.doi.org/10.5751/ ES-07985-200432

Perez, P., S. Aubert, W. Daré, R. Ducrot, N. Jones, J. Queste, G. Trébuil, and A. Van Paassen. 2010. Évaluation et suivi des effets de la démarche. Pages 153-181 in M. Étienne, editor. La modélisation d'accompagnement: une démarche participative en appui au développement durable. Éditions Quæ, Versailles, France.

Pretty, J. 2011. Interdisciplinary progress in approaches to address social-ecological and ecocultural systems. Environmental Conservation 38(2):127-139. http://dx.doi.org/10.1017/ $\underline{\mathrm{S} 0376892910000937}$

Ruckelshaus, M., E. McKenzie, H. Tallis, A. Guerry, G. Daily, P. Kareiva, S. Polasky, T. Ricketts, N. Bhagabati, S. A. Wood, and J. Bernhardt. 2015. Notes from the field: lessons learned from using ecosystem service approaches to inform real-world 
decisions. Ecological Economics 115:11-21. http://dx.doi. org/10.1016/j.ecolecon.2013.07.009

Ruppert-Winkel, C., R. Arlinghaus, S. Deppisch, K. Eisenack, D. Gottschlich, B. Hirschl, B. Matzdorf, T. Mölders, M. Padmanabhan, K. Selbmann, R. Ziegler, and T. Plieninger. 2015. Characteristics, emerging needs, and challenges of transdisciplinary sustainability science: experiences from the German SocialEcological Research Program. Ecology and Society 20(3):13. http://dx.doi.org/10.5751/es-07739-200313

Scholz, R. W., and G. Steiner. 2015a. The real type and ideal type of transdisciplinary processes: part I-theoretical foundations. Sustainability Science 10(4):527-544. http://dx.doi.org/10.1007/ s11625-015-0326-4

Scholz, R. W., and G. Steiner. 2015b. The real type and ideal type of transdisciplinary processes: part II-what constraints and obstacles do we meet in practice? Sustainability Science 10 (4):653-671. http://dx.doi.org/10.1007/s11625-015-0327-3

Shaner, W. W., P. F. Philipp, and W. R. Schmehl. 1982. Farming systems research and development: guidelines for developing countries. Westview Boulder, Colorado, USA. [online] URL: http://pdf.usaid.gov/pdf docs/Pnaal237.pdf

Sharma, M., M. Garcia, A. Qureshi, and L. R. Brown. 1996. Overcoming malnutrition: is there an ecoregional dimension? International Food Policy Research Institute, Washington, D.C., USA. [online] URL: http://www.ifpri.org/publication/overcomingmalnutrition

Strauss, A., and J. Corbin. 1990. Basics of qualitative research: techniques and procedures for developing grounded theory. Sage, Thousand Oaks, California, USA.

Stringer, L. C., A. J. Dougill, E. Fraser, K. Hubacek, C. Prell, and M. S. Reed. 2006. Unpacking "participation" in the adaptive management of social-ecological systems: a critical review. Ecology and Society 11(2):39. [online] URL: http://www. ecologyandsociety.org/vol11/iss2/art39/

Tallis, H., and J. Lubchenco. 2014. Working together: a call for inclusive conservation. Nature 515:27-28. http://dx.doi. org/10.1038/515027a

Tengö, M., E. S. Brondizio, T. Elmqvist, P. Malmer, and M. Spierenburg. 2014. Connecting diverse knowledge systems for enhanced ecosystem governance: the multiple evidence base approach. Ambio 43(5):579-591. http://dx.doi.org/10.1007/ $\underline{\text { s13280-014-0501-3 }}$

Thomas, G., and D. James. 2006. Reinventing grounded theory: some questions about theory, ground and discovery. British Educational Research Journal 32(6):767-795. http://dx.doi. org/10.1080/01411920600989412

Thompson, J. L. 2009. Building collective communication competence in interdisciplinary research teams. Journal of Applied Communication Research 37(3):278-297. http://dx.doi. org/10.1080/00909880903025911

Turner, B. L. II, K. J. Esler, P. Bridgewater, J. Tewksbury, N. Sitas, B. Abrahams, F. S. Chapin III, R. R. Chowdhury, P. Christie, S. Diaz, P. Firth, C. N. Knapp, J. Kramer, R. Leemans, M. Palmer, D. Pietri, J. Pittman, J. Sarukhán, R. Shackleton, R. Seidler, B. van Wilgen, and H. Mooney. 2016. Socio-environmental systems (SES) research: What have we learned and how can we use this information in future research programs. Current Opinion in Environmental Sustainability 19:160-168. http://dx.doi.org/10.1016/ j.cosust.2016.04.001

Vessuri, H. 2014. Cambios en las ciencias ante el impacto de la globalización. Revista de Estudios Sociales 50:167-173. http://dx. doi.org/10.7440/res50.2014.16

Vilsmaier, U., and D. J. Lang. 2015. Making a difference by marking the difference: constituting in-between spaces for sustainability learning. Current Opinion in Environmental Sustainability 16:51-55. http://dx.doi.org/10.1016/j.cosust.2015.07.019

Voß, J.-P., and B. Bornemann. 2011. The politics of reflexive governance: challenges for designing adaptive management and transition management. Ecology and Society 16(2):9. http://dx. doi.org/10.5751/es-04051-160209

Walker, B. H., J. M. Anderies, A. P. Kinzig, and P. Ryan, editors. 2006. Exploring resilience in social-ecological systems: comparative studies and theory development. Special feature Ecology and Society SF22. [online] URL: http://www. ecologyandsociety.org/issues/view.php/feature/22

Walter, A. I., S. Helgenberger, A. Wiek, and R. W. Scholz. 2007. Measuring societal effects of transdisciplinary research projects: design and application of an evaluation method. Evaluation and Program Planning 30(4):325-338. http://dx.doi.org/10.1016/j. evalprogplan.2007.08.002

Wiek, A., and B. Kay. 2015. Learning while transforming: solution-oriented learning for urban sustainability in Phoenix, Arizona. Current Opinion in Environmental Sustainability 16:29-36. http://dx.doi.org/10.1016/j.cosust.2015.07.001

Wittmayer, J. M., and N. Schäpke. 2014. Action, research and participation: roles of researchers in sustainability transitions. Sustainability Science 9(4):483-496. http://dx.doi.org/10.1007/ s11625-014-0258-4

Yarime, M., Y. Takeda, and Y. Kajikawa. 2010. Towards institutional analysis of sustainability science: a quantitative examination of the patterns of research collaboration. Sustainability Science 5:115-125. http://dx.doi.org/10.1007/ s11625-009-0090-4

Zierhofer, W., and P. Burger. 2007. Disentangling transdisciplinarity: an analysis of knowledge integration in problem-oriented research. Science and Technology Studies 20(1):51-74. 


\section{Research approaches for place based studies of social-ecological systems: insights gained}

\section{QUESTIONNAIRE}

Dear member of the PECS community,

You are receiving this email because you either participate in a PECS endorsed project, and/or you are (or have been) a member of the PECS Scientific Committee.

We are writing to you to seek your support in gathering insights from researchers working in the field how to best perform place-based socialecological sustainability research (hereafter 'PECS-type research'). For the PECS' vision and definitions of this type of research we refer to the Carpenter et al (2012) paper on PECS and emphasize these three features:

1. focused on understanding linkages between key social and ecological systems in a particular place or places;

2. concerned with identifying and promoting opportunities to improve sustainability in terms of social wellbeing, and the conservation of ecosystem integrity and biodiversity;

3. working, at least minimally, in partnership with non-academic stakeholders

You can fill in this survey for any project in which you have been recently involved that is consistent with the above definitions and aims. Your answers should relate to one specific project (even if you have been involved in several). If several representatives of the same project have been invited to fill this questionnaire please coordinate with colleagues to return only one survey per project.

The spirit of the survey is that you share with us your insights on what do you see now as key enabling features and key obstacles towards placed-based socialecological sustainability research.

This is a new survey based on the pilot conducted at the Moureze workshop.

We have divided the survey into six sections that relate to different aspects of the overall research approach adopted, or aspired to, within a particular study. These are described below.

1- Problem orientation features- How the project was conceived and designed, who is involved in this, and what are the key steps involved.

2- Research team features- What is the nature of the team (which researchers and stakeholders are included) as well as what is the nature of interactions between individuals and groups

3- Evaluative features- What the outputs and outcomes expected of the project, including those promised to the funders, those agreed upon with the stakeholders and those aimed for by the researchers involved. 
4- Conceptual features - Which are the key themes, concepts and approaches that have been adopted and acquired during the project.

5- Contextual features- What is the context of the research site (scale, socio-economic, political and historical context, geographic, spatial and temporal) and does this, and the context of the research itself (institutional setting, funding, types of links with stakeholders) influence the dynamics of the research process

6- Methodological features- What are the kinds of tools and types of methodological approach that were adopted as part of your research process.

We will be inquiring about your general thoughts on what are key features for each of these six categories, and what are desirable and undesirable aspects of these features using an open format. Then, we will use a closed format to inquire about which features are more or less important.

\section{Research ethics}

This survey asks you about challenges and experience of PECS-type research. Please respond as candidly as possible, but be mindful that data may conceivably be sensitive or reflect unfavorably on researchers, partners or funders. To mitigate the risk of inadvertent conflict or embarrassment, we will follow these ethical procedures.

- Your names and project details will be kept with the data

- The raw, non-anonymized data will be shared between the six team members only (Patty, Berta, Chinwe, Marja, Tim, Toby).

- The answers will be used to write a paper in the PECS special issue and possibly follow up studies.

- Completing the survey will qualify you for acknowledgement in papers that use the data; you will also be invited to coauthor the manuscript if you are interested to do contribute to the writing of the manuscript within the narrow timeline available.

- Draft text for publication using these survey data will be shared with survey respondents before submission for publication. You can then clarify statements, request that you or your project remain anonymous, or that the data are removed. If you have not responded within 3 weeks we will assume that you consent for the text to be submitted for publication.

We thank you very much in advance for your support with this endeavor!

Patty, Berta, Chinwe, Marja, Tim, and Toby

\section{REFERENCES}

Carpenter, S. R., C. Folke, A. Norström, O. Olsson, L. Schultz, B. Agarwal, P. Balvanera, B. Campbell, J. C. Castilla, W. Cramer, R. DeFries, P. Eyzaguirre, T. P. Hughes, S. Polasky, Z. Sanusi, R. Scholes, and M. Spierenburg. 2012. Program on ecosystem change and society: an international research strategy for integrated social-ecological systems. Current Opinion in Environmental Sustainability 4:134-138. 


\section{SURVEY}

\section{INFORMED CONSENT STATEMENT}

By filling out this survey you indicate that

- I understand how data from this survey will stored and used

- I give consent for my name and project details to be stored with these data

- I will have 3 weeks to approve publication of data provided by my survey before publication. If I do not respond within three weeks my consent for publication will be assumed.

- I will inform lead authors if I am interested in participating as an author and will provide contributions to the different drafts of the manuscript.

\section{GENERAL INFORMATION ON YOUR PROJECT}

Please provide us with some basic information about your project.

What is the title of your project?

Project start date Project end date

Where are your study site(s)?

Name of region/locality

Municipality

State

Country

Please provide a brief overview of what is the project about (150 words)

Where does the funding of the project come from?

How many people are directly (are paid by or have a fellowship directly linked to involved in the project?

PIs

Associate researchers

Postdocs

Graduate students

Undergraduate students

Stakeholders

Which is your role in the project? (please click as many as needed to represent the team that filled this survey)

PIs _

Associate researcher

Postdoc

Graduate student

Undergraduate student

Which countries are involved?

Country of lead institution

Other countries 
Who are the stakeholders involved?

Government

Local

State

Country levels

Land owners/managers

NGOs .

Business _

Other (please describe) 


\section{PROBLEM ORIENTATION FEATURES}

This section is about how the project was conceived and designed, who is involved in this, and what are the key steps involved.

\section{1- Current performance of your project}

Please provide us with your own list of up to three features of problem orientation features which you believe are important for PECS-type research, and rank the current performance of your project from 4 (excellent) to 1 (very poor) for each of these features.

Feature a. 1 (very poor), 2 (poor), 3 (good), 4 (excellent)

Feature b. 1 (very poor), 2 (poor), 3 (good), 4 (excellent)

Feature c. 1 (very poor), 2 (poor), 3 (good), 4 (excellent)

I'd be tempted to add an optional comments box under each of the questions 1-5. here as I think some good insights could be triggered by these questions as people go along, they might not have them to mind when they reach the end of the section.

\section{2- Desirable aspects}

Please tell us what do you think are desirable aspects of the above (and other if needed) problem orientation features (that you have either encountered or would like to see in future projects) towards achieving successful place-based social-ecological sustainability research.

Desirable aspect $a$.

Desirable aspect $b$.

Desirable aspect $c$.

Desirable aspect $d$.

Desirable aspect .

Desirable aspect $f$.

\section{$\underline{\text { 3- Undesirable aspects }}$}

Please tell us what do you think are undesirable aspects of the above (and other if needed) problem orientation features (that you have either encountered or feared to do so) towards achieving successful place-based social-ecological sustainability research.

Undesirable aspect $a$.

Undesirable aspect $b$.

Undesirable aspect $c$.

Undesirable aspect d.

Undesirable aspect e.

Undesirable aspect $f$.

\section{4-Enabling factors}


Please tell us what do you think have been the three key factors that have enabled a good performance of your research project with respect to problem orientation features.

Enabling factor 1

Enabling factor 2

Enabling factor 3

$\underline{\text { 5- Obstacles }}$

Please tell us what do you think have been the three key obstacles that have prevented a good performance of your research project with respect to problem orientation features.

Obstacle 1

Obstacle 2

Obstacle 3

6- General comments

Please share with us any other insights with respect to problem orientation features that you think will be very useful to others undertaking this kind of research in the future. 
7-Relative importance

Based on your experience, how important do you think each of these aspects of problem orientation features are for achieving successful place-based socialecological sustainability research.

The possible answers are: 1-completely unimportant, 2- fairly unimportant, 3important, 4- Essential. Please do not just score every feature as 4 unless you are really convinced that they are all essential.

Problem Orientation features

\begin{tabular}{|c|c|c|c|c|}
\hline Project initiation & \multicolumn{4}{|c|}{$\begin{array}{l}\text { Importance } \\
\text { Score }\end{array}$} \\
\hline $\begin{array}{l}\text { a. The project is triggered by a direct demand from } \\
\text { stakeholders }\end{array}$ & 1 & 2 & 3 & 4 \\
\hline $\begin{array}{l}\text { b. The project is triggered by the identification of a key } \\
\text { social-ecological sustainability issue }\end{array}$ & 1 & 2 & 3 & 4 \\
\hline $\begin{array}{l}\text { c. The project is a continuation of long-term research } \\
\text { occurring in at least one of the research sites }\end{array}$ & 1 & 2 & 3 & 4 \\
\hline The project is triggered by a suitable call for proposals & 1 & 2 & 3 & 4 \\
\hline Identification of the research question & 1 & 2 & 3 & 4 \\
\hline $\begin{array}{l}\text { e. The research question is identified by the whole } \\
\text { research team }\end{array}$ & 1 & 2 & 3 & 4 \\
\hline $\begin{array}{l}\text { f. The research question is identified in close collaboration } \\
\text { with the stakeholders }\end{array}$ & 1 & 2 & 3 & 4 \\
\hline \multicolumn{5}{|l|}{ Iterative refinement } \\
\hline The research question is refined as the project evolves & 1 & 2 & 3 & 4 \\
\hline $\begin{array}{l}\text { h. The research question and priorities within the project } \\
\text { are refined with direct involvement of stakeholders }\end{array}$ & 1 & 2 & 3 & 4 \\
\hline
\end{tabular}




\section{RESEARCH TEAM FEATURES}

This section is about the research team (comprising both researchers and stakeholders) and interactions within the team.

\section{1-Current performance of your project}

Please provide us with your own list of up to three features of research team features which you believe are important for PECS type research, and rank the current performance of your project from 4 (excellent) to 1 (very poor) for each of these features.

Feature a. 1 (very poor), 2 (poor), 3 (good), 4 (excellent)

Feature $b$. 1 (very poor), 2 (poor), 3 (good), 4 (excellent)

Feature $c$. 1 (very poor), 2 (poor), 3 (good), 4 (excellent)

\section{2- Desirable aspects}

Please tell us what do you think are desirable aspects of the above (and other if needed) research team features (that you have either encountered or would like to see in future projects) towards achieving successful place-based socialecological sustainability research.

Desirable aspect $a$.

Desirable aspect $b$.

Desirable aspect $c$.

Desirable aspect $d$.

Desirable aspect $e$.

Desirable aspect $f$.

\section{$\underline{\text { 3- Undesirable aspects }}$}

Please tell us what do you think are undesirable aspects of the above (and other if needed) research team features (that you have either encountered or feared to do so) towards achieving successful place-based social-ecological sustainability research.

Undesirable aspect $a$.

Undesirable aspect $b$.

Undesirable aspect c.

Undesirable aspect $d$.

Undesirable aspect e.

Undesirable aspect $f$.

\section{4- Enabling factors}

Please tell us what do you think have been the three key factors that have enabled a good performance of your research project with respect to research team features.

Enabling factor 1

Enabling factor 2

Enabling factor 3 
$\underline{\text { 5- Obstacles }}$

Please tell us what do you think have been the three key obstacles that have prevented a good performance of your research project with respect to research team features.

Obstacle 1

Obstacle 2

Obstacle 3

6- General comments

Please share with us any other insights with respect to problem orientation features that you think will be very useful to others undertaking this kind of research in the future. 


\section{7- Relative importance}

Based on your experience, how important do you think each of these research team features are for achieving successful place-based social-ecological sustainability research.

The possible answers are: 1-completely unimportant, 2- fairly unimportant, 3important, 4- Essential. Please do not just score every feature as 4 unless you are really convinced that they are all essential.

\begin{tabular}{|c|c|c|c|c|}
\hline \multirow{2}{*}{$\begin{array}{l}\text { Composition of the research team } \\
\text { a. The team incorporates researchers and students from different } \\
\text { disciplines within the social and ecological sciences }\end{array}$} & \multicolumn{4}{|c|}{$\begin{array}{l}\text { Importance } \\
\text { Score }\end{array}$} \\
\hline & 1 & 2 & 3 & 4 \\
\hline $\begin{array}{l}\text { b. Local/regional stakeholders are embedded as full members of } \\
\text { the team }\end{array}$ & 1 & 2 & 3 & 4 \\
\hline c. The team incorporates both specialists and generalists & 1 & 2 & 3 & 4 \\
\hline $\begin{array}{l}\text { eople that are embedded in or deeply } \\
\text { necessarily themselves stakeholders) }\end{array}$ & 1 & 2 & 3 & 4 \\
\hline $\begin{array}{l}\text { udes researchers and students from research and } \\
\text { utions local to study sites }\end{array}$ & 1 & 2 & 3 & 4 \\
\hline $\begin{array}{l}\text { f. The team includes more senior researchers as well as young } \\
\text { scholars }\end{array}$ & 1 & 2 & 3 & 4 \\
\hline $\begin{array}{l}\text { g. The te } \\
\text { disciplin }\end{array}$ & 1 & 2 & 3 & 4 \\
\hline \multicolumn{5}{|l|}{ Attitudes of team members } \\
\hline od interpersonal skills (emp & 1 & 2 & 3 & 4 \\
\hline $\begin{array}{l}\text { b. Te } \\
\text { towa }\end{array}$ & 1 & 2 & 3 & 4 \\
\hline $\begin{array}{l}\text { c. Te } \\
\text { rese }\end{array}$ & 1 & 2 & 3 & 4 \\
\hline $\begin{array}{l}\text { d. Tea } \\
\text { succe: }\end{array}$ & 1 & 2 & 3 & 4 \\
\hline \multicolumn{5}{|l|}{ Communication } \\
\hline $\begin{array}{l}\text { lows for common understanding of } \\
\text { rk }\end{array}$ & 1 & 2 & 3 & 4 \\
\hline communications across the team (not just & 1 & 2 & 3 & 4 \\
\hline $\begin{array}{l}\text { c. Face to face meetings are held at least once a year among all the } \\
\text { different members of the team }\end{array}$ & 1 & 2 & 3 & 4 \\
\hline $\begin{array}{l}\text { d. A boundary object or collaborative platform is available to foster } \\
\text { exchange (please specify if so) }\end{array}$ & 1 & 2 & 3 & 4 \\
\hline $\begin{array}{l}\text { e. Trust between project participants has already been built, prior } \\
\text { to project inception, over a sustained period (years) }\end{array}$ & 1 & 2 & 3 & 4 \\
\hline \multicolumn{5}{|l|}{ Management } \\
\hline a. Ro & 1 & 2 & 3 & 4 \\
\hline b. Rules for decision-making are clearly defined & 1 & 2 & 3 & 4 \\
\hline
\end{tabular}


c. Organizational structure for decision making allows all the members of the team to feel represented

d. Budget issues are openly discussed among leaders of the different teams involved

\begin{tabular}{|l|l|l|l|}
\hline 1 & 2 & 3 & 4 \\
1 & 2 & 3 & 4 \\
\hline
\end{tabular}




\section{EVALUATIVE FEATURES}

This section is about outputs and outcomes expected of the project, including those promised to the funders, those agreed upon with the stakeholders and those aimed for by the researchers involved (which may be explicit or not).

\section{1- Current performance of your project}

Please provide us with your own list of up to three features of evaluative features which you believe are important for PECS type research, and rank the current performance of your project from 4 (excellent) to 1 (very poor) for each of these features.

Feature a. 1 (very poor), 2 (poor), 3 (good), 4 (excellent)

Feature b. 1 (very poor), 2 (poor), 3 (good), 4 (excellent)

Feature c. 1 (very poor), 2 (poor), 3 (good), 4 (excellent)

\section{2- Desirable aspects}

Please tell us what do you think are desirable aspects of the above (and other if needed) evaluative features (that you have either encountered or would like to see in future projects) towards achieving successful place-based social-ecological sustainability research.

Desirable aspect $a$.

Desirable aspect $b$.

Desirable aspect $c$.

Desirable aspect $d$.

Desirable aspect .

Desirable aspect $f$.

\section{$\underline{\text { 3- Undesirable aspects }}$}

Please tell us what do you think are undesirable aspects of the above (and other if needed) evaluative features (that you have either encountered or feared to do so) towards achieving successful place-based social-ecological sustainability research.

Undesirable aspect $a$.

Undesirable aspect $b$.

Undesirable aspect c.

Undesirable aspect $d$.

Undesirable aspect e.

Undesirable aspect $f$.

\section{4- Enabling factors}

Please tell us what do you think have been the three key factors that have enabled a good performance of your research project with respect to evaluative features.

Enabling factor 1

Enabling factor 2

Enabling factor 3

\section{$\underline{\text { 5- Obstacles }}$}


Please tell us what do you think have been the three key obstacles that have prevented a good performance of your research project with respect to evaluative features.

Obstacle 1

Obstacle 2

Obstacle 3

6- General comments

Please share with us any other insights with respect to problem orientation features that you think will be very useful to others undertaking this kind of research in the future. 
7- Relative importance

Based on your experience, how important do you think each of these types of products and outcomes are important for the success of PECS-type research.

The possible answers are: 1-completely unimportant, 2- fairly unimportant, 3important, 4- Essential. Please do not just score every feature as 4 unless you are really convinced that they are all essential.

\begin{tabular}{|c|c|c|c|c|}
\hline \multirow{2}{*}{$\begin{array}{l}\text { Products expected from the research team } \\
\text { a. Scientific papers in international peer-reviewed indexed journals }\end{array}$} & \multicolumn{4}{|c|}{$\begin{array}{l}\text { Importance } \\
\text { Score }\end{array}$} \\
\hline & 1 & 2 & 3 & 4 \\
\hline $\begin{array}{l}\text { b. Policy briefs aimed at local, sub-national or national level } \\
\text { decision-makers }\end{array}$ & 1 & 2 & 3 & 4 \\
\hline c. Policy support tools (e.g. decision-support systems) & 1 & 2 & 3 & 4 \\
\hline d. Manage & 1 & 2 & 3 & 4 \\
\hline $\begin{array}{l}\text { e. Outreach } \\
\text { areas }\end{array}$ & 1 & 2 & 3 & 4 \\
\hline & 1 & 2 & 3 & 4 \\
\hline 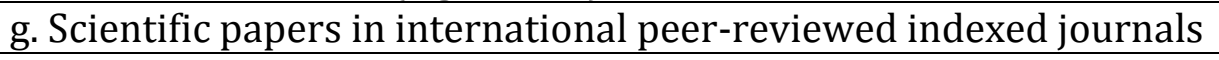 & 1 & 2 & 3 & 1 \\
\hline \multicolumn{5}{|l|}{ Outcomes expected from the research team and process } \\
\hline nembers have good interpersonal skills (er & 1 & 2 & 3 & 4 \\
\hline $\begin{array}{l}\text { b. Building } \\
\text { within the }\end{array}$ & 1 & 2 & 3 & 4 \\
\hline c. Strengthening local informal institutions to foster decision- & 1 & 2 & 3 & 4 \\
\hline $\begin{array}{l}\text { d. Strengthening sub-national and national formal institutions to } \\
\text { foster decision-making }\end{array}$ & 1 & 2 & 3 & 4 \\
\hline
\end{tabular}




\section{CONCEPTUAL FEATURES}

In this section we examine the key themes, concepts and approaches that are deemed most relevant for undertaking place-based social-ecological research.

\section{1- Current performance of your project}

Please provide us with your own list of up to three features of conceptual

features which you believe are important for PECS type research, and rank the current performance of your project from 4 (excellent) to 1 (very poor) for each of these features.

Feature a. 1 (very poor), 2 (poor), 3 (good), 4 (excellent)

Feature b. 1 (very poor), 2 (poor), 3 (good), 4 (excellent)

Feature $c$. 1 (very poor), 2 (poor), 3 (good), 4 (excellent)

\section{2- Desirable aspects}

Please tell us what do you think are desirable aspects of the above (and other if needed) conceptual features (that you have either encountered or would like to see in future projects) towards achieving successful place-based social-ecological sustainability research.

Desirable aspect $a$. Desirable aspect $b$. Desirable aspect $c$. Desirable aspect d. Desirable aspect . Desirable aspect $f$.

\section{$\underline{\text { 3- Undesirable aspects }}$}

Please tell us what do you think are undesirable aspects of the above (and other if needed) conceptual features (that you have either encountered or feared to do so) towards achieving successful place-based social-ecological sustainability research.

Undesirable aspect a.

Undesirable aspect $b$.

Undesirable aspect c.

Undesirable aspect $d$.

Undesirable aspect $e$.

Undesirable aspect $f$.

\section{4- Enabling factors}

Please tell us what do you think have been the three key factors that have enabled a good performance of your research project with respect to conceptual features.

Enabling factor 1

Enabling factor 2

Enabling factor 3 
$\underline{\text { 5- Obstacles }}$

Please tell us what do you think have been the three key obstacles that have prevented a good performance of your research project with respect to conceptual features.

Obstacle 1

Obstacle 2

Obstacle 3

\section{6-General comments}

Please share with us any other insights with respect to problem orientation features that you think will be very useful to others undertaking this kind of research in the future. 


\section{7- Relative importance}

Based on your experience, how important do you think each of these aspects of conceptual features are for achieving successful place-based social-ecological sustainability research.

The possible answers are: 1-completely unimportant, 2- fairly unimportant, 3important, 4- Essential. Please do not just score every feature as 4 unless you are really convinced that they are all essential.

\begin{tabular}{|l|l|l|l|l|}
\hline Areas of assessment that should be included are & \multicolumn{4}{|c|}{ Importance } \\
& \multicolumn{2}{|c|}{ Score } \\
\hline a. Biodiversity & 1 & 2 & 3 & 4 \\
\hline b. Ecological processes & 1 & 2 & 3 & 4 \\
\hline c. Biophysical conditions & 1 & 2 & 3 & 4 \\
\hline d. Economic activities & 1 & 2 & 3 & 4 \\
\hline e. Wellbeing & 1 & 2 & 3 & 4 \\
\hline f. Governance arrangements & 1 & 2 & 3 & 4 \\
\hline g. Informal institutions & 1 & 2 & 3 & 4 \\
\hline $\begin{array}{l}\text { Conceptual approaches used as organizing frameworks for social-ecological } \\
\text { sustainability research }\end{array}$ & 1 & 2 & 3 & 4 \\
\hline a. Ecosystem services & 1 & 2 & 3 & 4 \\
\hline b. Equity and justice & 1 & 2 & 3 & 4 \\
\hline c. Historical processes and legacy effects & 1 & 2 & 3 & 4 \\
\hline $\begin{array}{l}\text { d. Knowledge sought from both conventional and traditional } \\
\text { sources }\end{array}$ & & & \\
\hline e. Resilience thinking & 1 & 2 & 3 & 4 \\
\hline f. Transition theory & 1 & 2 & 3 & 4 \\
\hline $\begin{array}{l}\text { g. Knowledge sought from both conventional and traditional } \\
\text { sources }\end{array}$ & 1 & 2 & 3 & 4 \\
\hline Use of a conceptual framework & & & \\
\hline $\begin{array}{l}\text { a. A conceptual framework is available to guide the research team } \\
\text { and processes }\end{array}$ & 1 & 2 & 3 & 4 \\
\hline
\end{tabular}

If a conceptual framework is available please choose the appropriate option for describing how it was developed:
a. The conceptual framework was "“borrowed” from a published source
b. The conceptual framework was "adapted" from a published source
c. The conceptual framework was developed from first principles by a small group of lead researchers
d. The conceptual framework was developed through participation of the majority of researchers
e. The conceptual frameworks was developed jointly by researchers and stakeholders
f. Other 


\section{CONTEXTUAL FEATURES}

This section asks about the particular context of the research site (scale, socioeconomic, political and historical context, geographic, spatial and temporal) and the particular research context (institutional setting, funding, types of links with stakeholders), and how these influence the dynamics of the research process.

\section{1-Current performance of your project}

Please provide us with your own list of up to three features of contextual features which you believe are important for PECS type research, and rank the current performance of your project from 4 (excellent) to 1 (very poor) for each of these features.

Feature a. 1 (very poor), 2 (poor), 3 (good), 4 (excellent)

Feature b. 1 (very poor), 2 (poor), 3 (good), 4 (excellent)

Feature $c$. 1 (very poor), 2 (poor), 3 (good), 4 (excellent)

\section{2- Desirable aspects}

Please tell us what do you think are desirable aspects of the above (and other if needed) contextual features (that you have either encountered or would like to see in future projects) towards achieving successful place-based social-ecological sustainability research.

Desirable aspect $a$.

Desirable aspect $b$.

Desirable aspect $c$.

Desirable aspect $d$.

Desirable aspect .

Desirable aspect $f$.

\section{$\underline{\text { 3- Undesirable aspects }}$}

Please tell us what do you think are undesirable aspects of the above (and other if needed) contextual features (that you have either encountered or feared to do so) towards achieving successful place-based social-ecological sustainability research.

Undesirable aspect a.

Undesirable aspect $b$.

Undesirable aspect c.

Undesirable aspect $d$.

Undesirable aspect e.

Undesirable aspect $f$.

\section{4- Enabling factors}

Please tell us what do you think have been the three key factors that have enabled a good performance of your research project with respect to contextual features.

Enabling factor 1

Enabling factor 2

Enabling factor 3 


\section{$\underline{\text { 5- Obstacles }}$}

Please tell us what do you think have been the three key obstacles that have prevented a good performance of your research project with respect to problem orientation features.

Obstacle 1

Obstacle 2

Obstacle 3

\section{6- General comments}

Please share with us any other insights with respect to problem orientation features that you think will be very useful to others undertaking this kind of research in the future. 


\section{7- Relative importance}

Based on your experience, how important do you think each of these aspects of contextual features are for achieving successful place-based social-ecological sustainability research.

The possible answers are: 1-completely unimportant, 2- fairly unimportant, 3important, 4- Essential. Please do not just score every feature as 4 unless you are really convinced that they are all essential.

\begin{tabular}{|c|c|c|c|c|}
\hline \multirow{2}{*}{$\begin{array}{l}\text { Context and research design } \\
\text { a. Multiple sites are selected to capture a range of biophysical and } \\
\text { societal conditions to foster comparison }\end{array}$} & \multicolumn{4}{|c|}{$\begin{array}{c}\text { Importance } \\
\text { Score }\end{array}$} \\
\hline & 1 & 2 & 3 & 4 \\
\hline b. Multiple spatial scales are addressed & 1 & 2 & 3 & 4 \\
\hline $\begin{array}{l}\text { c. The spatial scales at which decision-making takes place are } \\
\text { explicitly taken into account }\end{array}$ & 1 & 2 & 3 & 4 \\
\hline d. The project encompasses research over the long-term & 1 & 2 & 3 & 4 \\
\hline $\begin{array}{l}\text { e. Few enough study sites are included to allow for deep } \\
\text { understanding at each }\end{array}$ & 1 & 2 & 3 & 4 \\
\hline $\begin{array}{l}\text { f. Multiple sites a } \\
\text { societal conditior }\end{array}$ & 1 & 2 & 3 & 4 \\
\hline g. Multiple spatial scales are addressed & 1 & 2 & 3 & 4 \\
\hline \multicolumn{5}{|l|}{ Understanding of key characteristics of research site } \\
\hline $\begin{array}{l}\text { a. All main type(s) of ecosystems (including agroecos } \\
\text { study site }\end{array}$ & 1 & 2 & 3 & 4 \\
\hline al historical context is addressed & 1 & 2 & 3 & 4 \\
\hline c. The ke & 1 & 2 & 3 & 4 \\
\hline d. The & 1 & 2 & 3 & 4 \\
\hline drivers & 1 & 2 & 3 & 4 \\
\hline le governance influ & 1 & 2 & 3 & 4 \\
\hline h feasibility & 1 & 2 & 3 & 4 \\
\hline $\begin{array}{l}\text { a. Funding is obtained from both the countries where study sites } \\
\text { are located as well as countries where other members of the team } \\
\text { are located }\end{array}$ & 1 & 2 & 3 & 4 \\
\hline g is available for this kind of research & 1 & 2 & 3 & 4 \\
\hline c. Funding & 1 & 2 & 3 & 4 \\
\hline $\begin{array}{l}\text { d. Home institutions of researchers foster/recognize the } \\
\text { importance of trans-disciplinary research }\end{array}$ & 1 & 2 & 3 & 4 \\
\hline \multicolumn{5}{|l|}{ Context of research implications } \\
\hline $\begin{array}{l}\text { a. Ethical guidelines of interaction with stakeholders and other } \\
\text { local/regional actors, and among team members are explicitly } \\
\text { taken into account }\end{array}$ & 1 & 2 & 3 & 4 \\
\hline $\begin{array}{l}\text { b. The direction of research is protected from manipulation by } \\
\text { powerful stakeholders }\end{array}$ & 1 & 2 & 3 & 4 \\
\hline $\begin{array}{l}\text { c. Research results are used for original project aims rather than } \\
\text { stakeholders promoting their own agenda }\end{array}$ & 1 & 2 & 3 & 4 \\
\hline
\end{tabular}




\section{METHODOLOGICAL FEATURES}

In this section we explore which tools and types of methodological approaches constitute the research process. Irrespective of what actually happened in the project we are looking for what you think should have been done.

\section{1- Current performance of your project}

Please provide us with your own list of up to three features of methodological features which you believe are important for PECS type research, and rank the current performance of your project from 4 (excellent) to 1 (very poor) for each of these features.

Feature a. 1 (very poor), 2 (poor), 3 (good), 4 (excellent)

Feature $b$. 1 (very poor), 2 (poor), 3 (good), 4 (excellent)

Feature c. 1 (very poor), 2 (poor), 3 (good), 4 (excellent)

2- Desirable aspects

Please tell us what do you think are desirable aspects of the above (and other if needed) contextual features (that you have either encountered or would like to see in future projects) towards achieving successful place-based social-ecological sustainability research.

Desirable aspect $a$.

Desirable aspect $b$.

Desirable aspect $c$.

Desirable aspect $d$.

Desirable aspect .

Desirable aspect $f$.

\section{3- Undesirable aspects}

Please tell us what do you think are undesirable aspects of the above (and other if needed) contextual features (that you have either encountered or feared to do so) towards achieving successful place-based social-ecological sustainability research.

Undesirable aspect $a$.

Undesirable aspect $b$.

Undesirable aspect c.

Undesirable aspect d.

Undesirable aspect e.

Undesirable aspect $f$.

\section{4- Enabling factors}

Please tell us what do you think have been the three key factors that have enabled a good performance of your research project with respect to problem orientation features.

Enabling factor 1

Enabling factor 2

Enabling factor 3 


\section{$\underline{\text { 5- Obstacles }}$}

Please tell us what do you think have been the three key obstacles that have prevented a good performance of your research project with respect to problem orientation features.

Obstacle 1

Obstacle 2

Obstacle 3

\section{6- General comments}

Please share with us any other insights with respect to problem orientation features that you think will be very useful to others undertaking this kind of research in the future. 


\section{7-Relative importance}

Based on your experience, how important do you think each of these aspects of methodological features are for achieving successful place-based socialecological sustainability research.

The possible answers are: 1-completely unimportant, 2- fairly unimportant, 3important, 4- Essential. Please do not just score every feature as 4 unless you are really convinced that they are all essential.

\begin{tabular}{|c|c|c|c|c|}
\hline Nature of research methods & \multicolumn{4}{|c|}{$\begin{array}{l}\text { Importance } \\
\text { Score }\end{array}$} \\
\hline $\begin{array}{l}\text { a. The projects uses both qualitative and quantitative } \\
\text { methodological approaches }\end{array}$ & 1 & 2 & 3 & 4 \\
\hline b. The project uses both methods from Natural and Social Science & 1 & 2 & 3 & 4 \\
\hline $\begin{array}{l}\text { c. The project uses participatory methods, including individual and } \\
\text { deliberative tools }\end{array}$ & 1 & 2 & 3 & 4 \\
\hline \multicolumn{5}{|l|}{ Nature of methodological approaches } \\
\hline a. The project uses participatory action research approach & 1 & 2 & 3 & 4 \\
\hline $\begin{array}{l}\text { b. The project incorporates explicitly uncertainty in its } \\
\text { methodological approaches }\end{array}$ & 1 & 2 & 3 & 4 \\
\hline c. The methods allow for triangulation of the information & 1 & 2 & 3 & 4 \\
\hline
\end{tabular}

THANK YOU FOR YOUR TIME! 